\title{
Principles for Fisheries Management in Areas Beyond National Juriscliction-the Essential Role of Incentive-Based Approaches
}

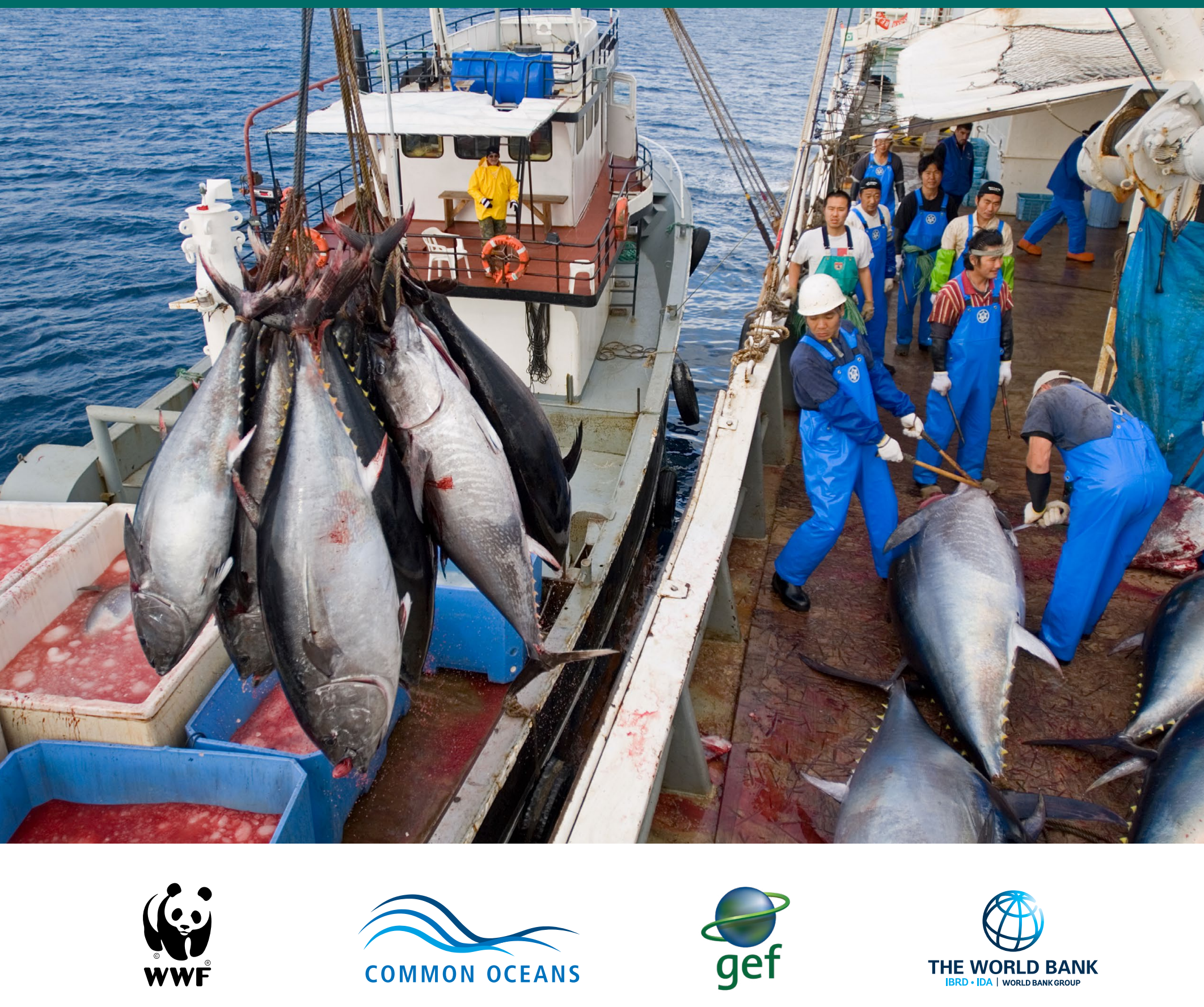


a

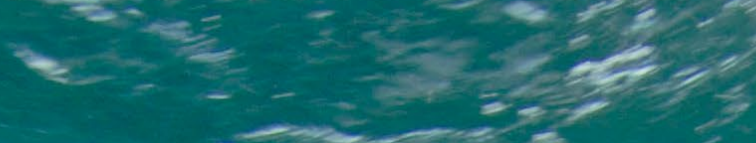

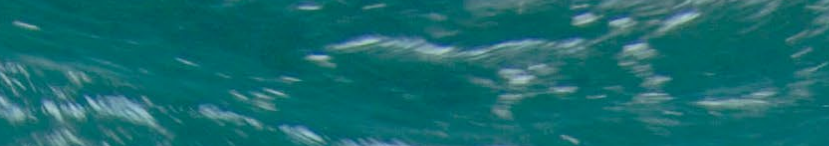
$e^{2}=-$

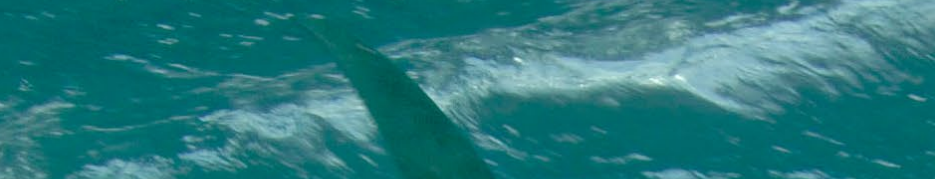
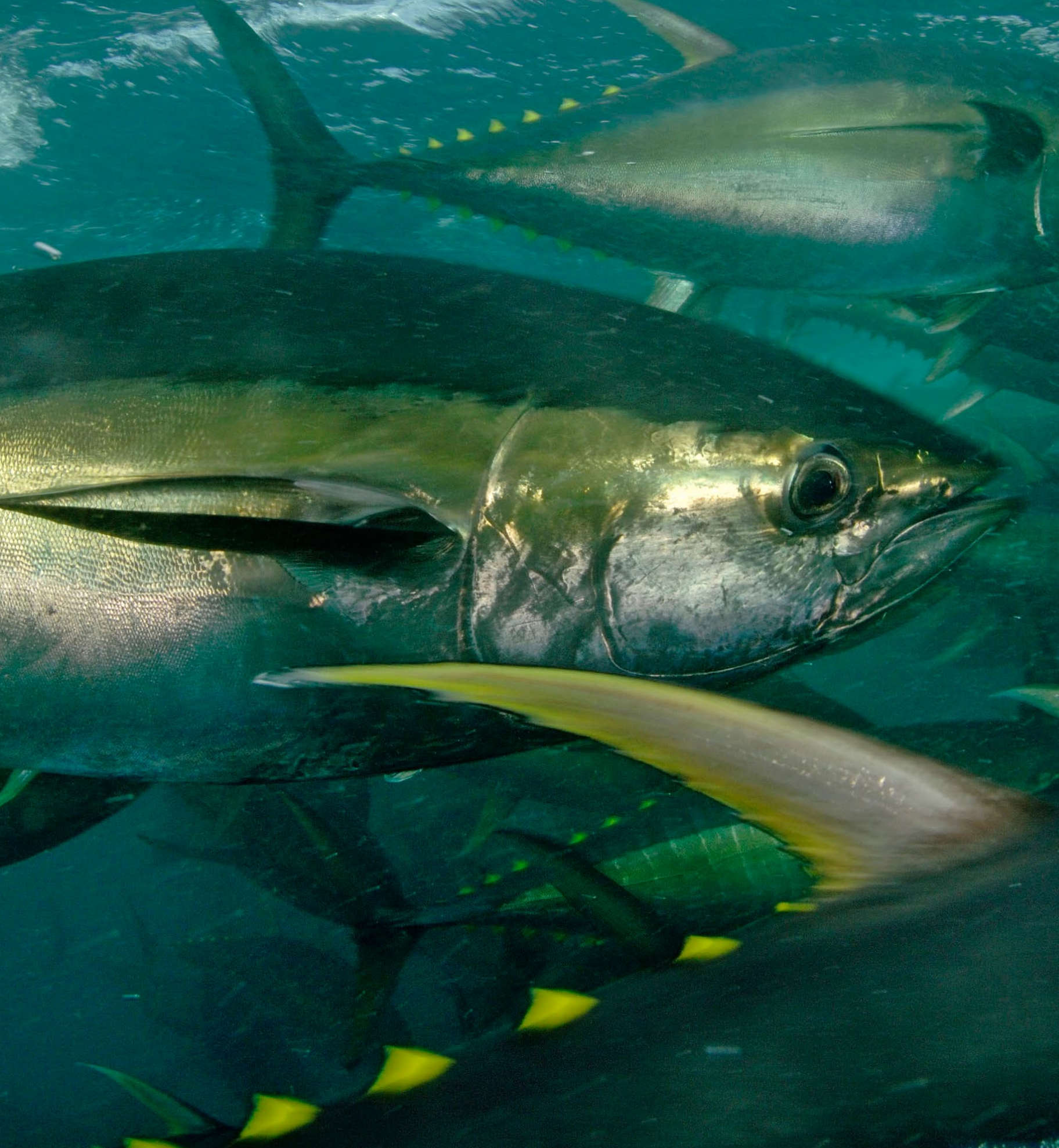

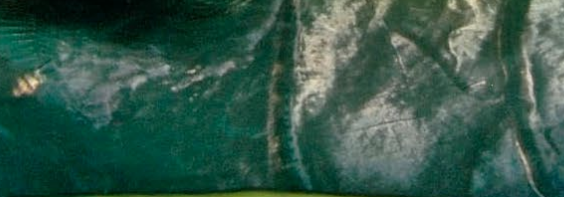

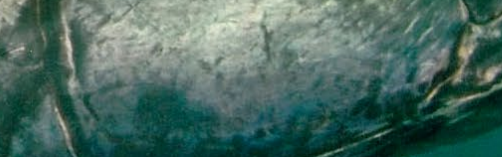
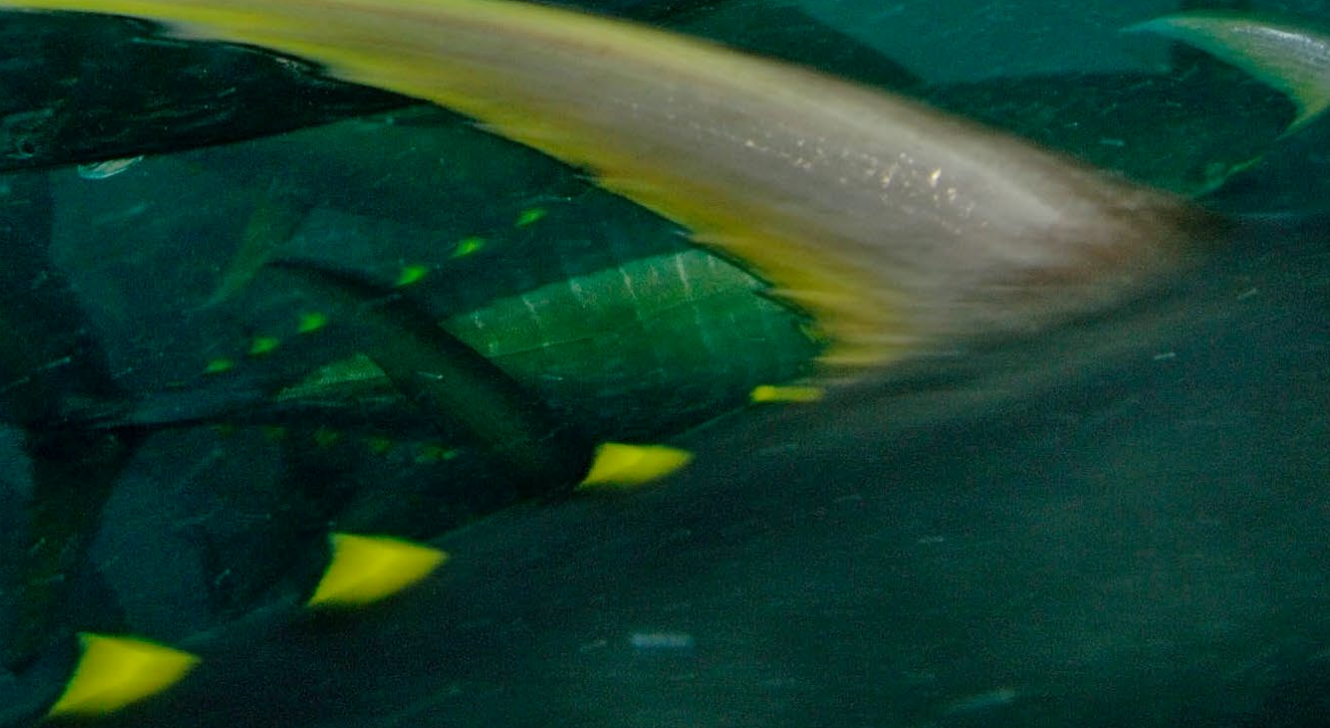

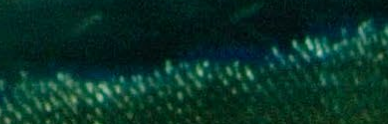

. 


\section{Principles for Fisheries Management in Areas Beyond National Jurisdiction-the Essential Role of Incentive-Based Approaches}

Authors in alphabetical order: ${ }^{1}$ James Anderson, Frank Asche, Richard Barnes, Simon Bush, Brad Gentner, Charles Hufflett, Gary Libecap, Vishwanie Maharaj, Lindie Nelson, Wez Norris, Giansandro Perotti, Uwe Tietze, Kelly Wachowicz

DECEMBER 2018 

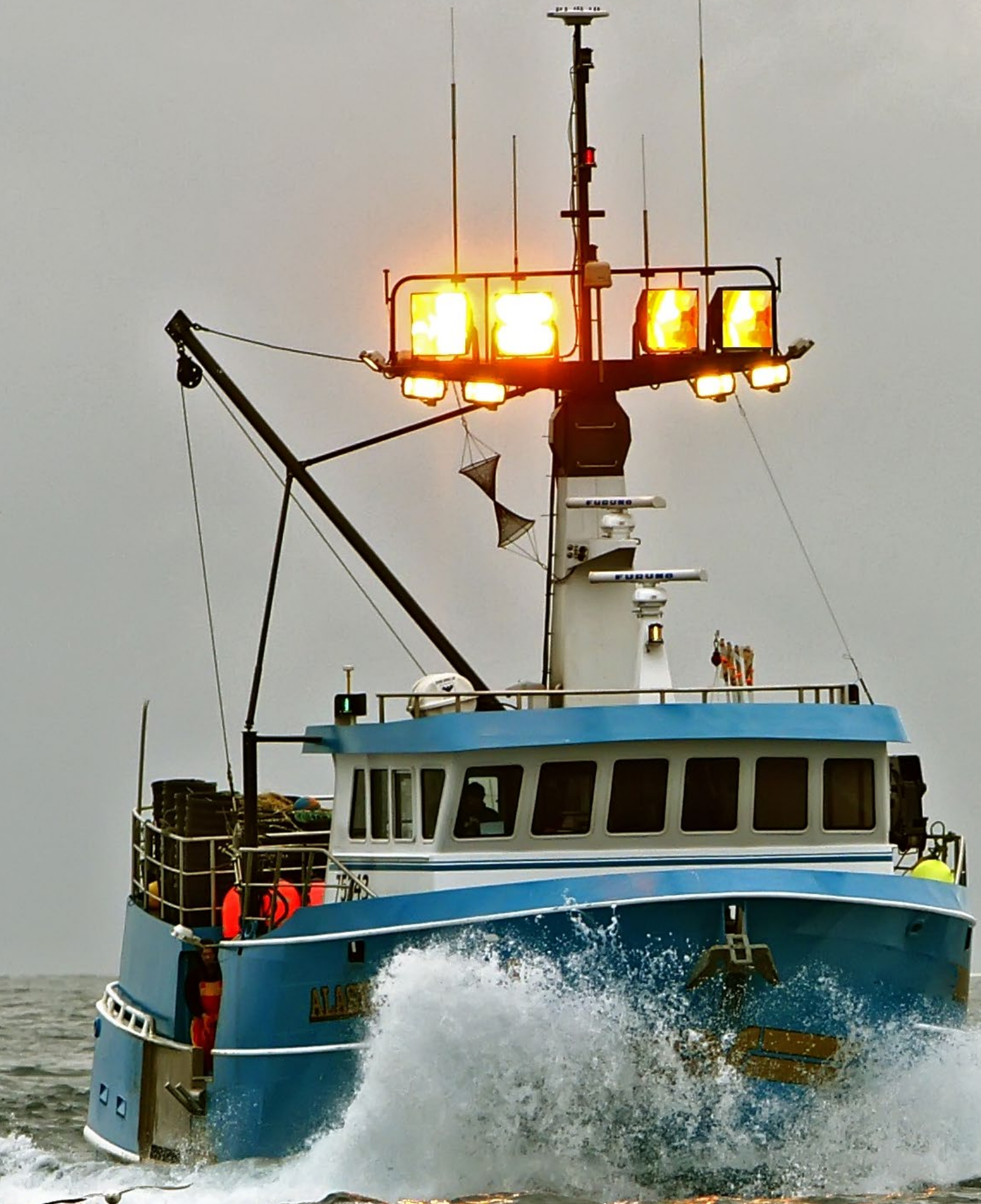


\section{PREFACE}

This publication was prepared under the auspices of a multidisciplinary Global Think Tank (GloTT) for the World Bank's Ocean Partnerships for Sustainable Fisheries and Biodiversity Conservation: Models for Innovation and Reform (OPP). The World Bank's OPP is one of four projects under the Global Environment Facility (GEF) Areas Beyond National Jurisdiction (ABNJ) Program and World Wildlife Fund-Inc. (WWF-US) is one of the partners under this GEF-ABNJ or Common Oceans umbrella. The technical director for the work of the GloTT and technical editor of this publication is Vishwanie Maharaj, Oceans, WWF-US.

The GloTT is an advisory body comprised of a multidisciplinary group of globally experienced specialists who reviewed the design of OPP regional business cases and oversaw the development of technical reports in support of this publication. This diverse group is comprised of experts on the tuna industry, fisheries financing, economics, international law, management of tuna fisheries and ecology of highly migratory fisheries. GloTT insights were captured through facilitated meetings and direct input to provide a broad vision for management of highly migratory fisheries with a high seas component (ABNJ fisheries).
This publication draws from and is complemented by two detailed technical reports. One of these reports, prepared by Richard Barnes, focuses on the barriers and opportunities for the adoption of incentive-based tools for ABNJ fisheries at the global and regional scales. Barnes evaluates the impacts of applicable legal instruments, related regimes, and other relevant institutions on the performance of incentives applied to ABNJ fisheries. The other technical report, prepared by Brad Gentner, covers incentivebased management at the local and regional scales, with an emphasis on pre-implementation, implementation, design, and performance of programs. The Gentner report assesses selected programs in the convention areas of the five tuna regional management bodies and captures relevant details from the OPP regional projects.

Many of the findings and recommendations in this publication are applicable to deep sea fisheries that are resident in ABNJ. The deep sea $A B N J$ fisheries support industries and face similar challenges to the pelagic ABNJ fisheries. Another Common Oceans project focuses on the sustainable use of deep sea living resources and biodiversity. 


\section{Table of Contents}

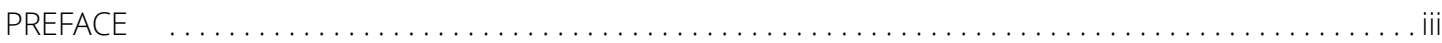

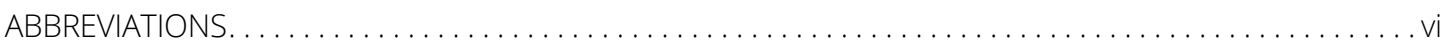

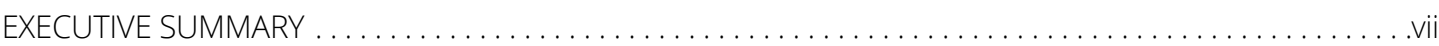

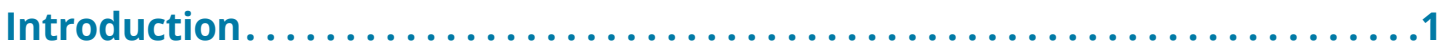

Instruments, Interventions, and Drivers of Change..............

Principle 1: Ensure Compatible Instrument Combinations. ...........11

Principle 2: Calibrate Interventions Towards Points of

Least Resistance, Lowest Cost, and Maximum Impact ............... 13

Low-Cost Interventions............................................... 13

Low-Conflict Interventions............................................ 13

Targeted Interventions.............................................. 14

Principle 3: Sequence or Scale Interventions as Necessary

to Achieve Goals . . . . . . . . . . . . . . . . . . . . . . . . . . . 17

Principle 4: Empower Participants Best Able to Act as Surrogate

Regulators and Enable Voluntary Initiatives . . . . . . . . . . . . . . . 19

Delegated Legal Power....................................................... 19

Influencing the Regulatory Process ....................................... 20

Principle 5: Maximize Opportunities for Net Gain Outcomes ...........23

Principle 6: Consider and Harness the Responsiveness of

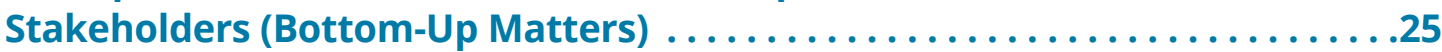

Principle 7: Consider Top-Down Relationships, Opportunities,

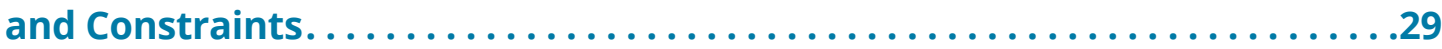

Legal and Institutional Constraints......................................... 29

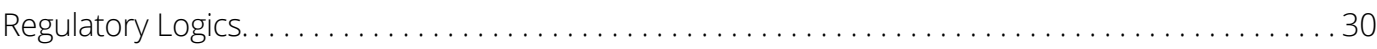

Principle 8: Assess and Adapt the Smart Mix in Light of

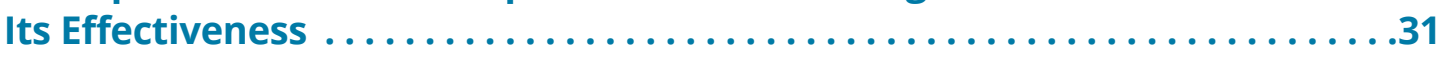

Principle 9: Assess Opportunities for Better Interventions . . . . . . . . . . 33

Market Changes..................................................... 34

Harvesting Technology .................................................. 34 


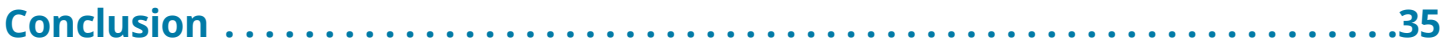

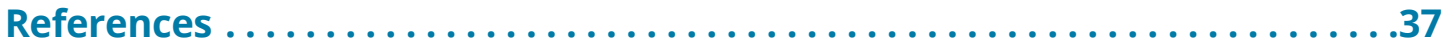

Appendix: Case Studies . . . . . . . . . . . . . . . . . . . . . 43

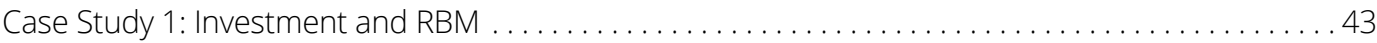

Case Study 2: Caribbean Projects Under the OPP............................. 44

Case Study 3: The Role of Key Actors in the Value Chain ............................. 46

Case Study 4: The Parties to the Nauru Agreement

and the Development of the Vessel Day Scheme............................. 47

Case Study 5: Fishery Certification Schemes. . . . . . . . . . . . . . . . . . . . . . . . . . 51

Case Study 6: "Isda Strategy" . . . . . . . . . . . . . . . . . . . . . . . . . . . . . . . . . . . . 52

Case Study 7: Allocation Issues in International Fisheries ......................... 53

Case Study 8: Review of UNFSA—Reflective International Law-Making . . . . . . . . . . . . . . 54

Case Study 9: Management Options and Investment Potential in IATTC .................. 55

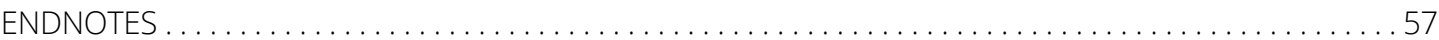




\section{Abbreviations}

\begin{tabular}{|c|c|c|c|}
\hline ABNJ & Area Beyond National Jurisdiction & $\mathrm{PL}$ & Pole and Line \\
\hline \multirow[t]{2}{*}{ AIDCP } & \multirow{2}{*}{$\begin{array}{l}\text { Agreement on the International Dolphin } \\
\text { Conservation Program }\end{array}$} & PNA & Parties to the Nauru Agreement \\
\hline & & PPP & Public Private Partnerships \\
\hline CDS & Catch Documentation Scheme & PRI & \\
\hline DML & Dolphin Mortality Limit & PS & Purse Seine \\
\hline EEZ & Exclusive Economic Zone & RBM & Rights Based Management \\
\hline EM & Electronic Monitoring & RFMO & Regional Fishery Management Organization \\
\hline EPO & Eastern Pacific Ocean & SIDS & Small Island Developing State \\
\hline FAD & Fish Aggregating Device & TAC & Total Allowable Catch \\
\hline FIP & Fishery Improvement Project & TAE & Total Allowable Effort \\
\hline FPI & Fishery Performance Indicators & UN & United Nations \\
\hline GloTt & Global Think Tank & UNFSA & UN Fish Stocks Agreement \\
\hline IATTC & Inter-American Tropical Tuna Commission & UNCLOS & UN Convention on the Laws of the Sea \\
\hline ICCAT & $\begin{array}{l}\text { International Commission for Conservation } \\
\text { of Atlantic Tunas }\end{array}$ & USA & United States of America \\
\hline ISSF & Internal Seafood Sustainability Foundation & VDS & Vessel Day Scheme \\
\hline IVQ & Individual Vessel Quota & VMS & Vessel Monitoring System \\
\hline IUU & Illegal, Unreported or Unregulated & WCPFC & $\begin{array}{l}\text { Commission for the Conservation and } \\
\text { management of Highly Migratory Fish }\end{array}$ \\
\hline LL & Long Line & & Stocks in the Western and Central Pacific \\
\hline MCS & Monitoring, Control and Surveillance & WCPO & West Central Pacific Ocean \\
\hline MSC & Marine Stewardship Council & & \\
\hline NGO & Non-Governmental Organization & & \\
\hline NMFS & National Marine Fisheries Service & & \\
\hline NOAA & $\begin{array}{l}\text { National Oceanic and Atmospheric } \\
\text { Administration }\end{array}$ & & \\
\hline OPP & $\begin{array}{l}\text { Ocean Partnerships for Sustainable } \\
\text { Fisheries and Biodiversity Conservation - } \\
\text { Models for Innovation and Reform }\end{array}$ & & \\
\hline
\end{tabular}




\section{Executive Summary}

Fisheries that intersect with the high seas, or areas beyond national jurisdictions (ABNJ), are ecologically, institutionally, and politically complex. These fisheries also generate enormous economic and social benefits, and have the potential to generate even greater benefits and wealth under improved management regimes that incorporate incentives.

Governance gaps within international instruments for ABNJ fisheries are well recognized. However, reform through a global process is slow and highly contingent upon political will. While the need for incentives is critical to make up for the gaps in governance, the gaps themselves and the multilateral nature of ABNJ fisheries management make it impossible to achieve first best solutions. Thus, a new theory of change for ABNy fisheries is needed that mixes State regulation and economic incentives in a way that achieves "smart," sustainable, and equitable management.

Drawing on the vast multidisciplinary literature and insights from the Common Oceans Global Think Tank on ABNJ fisheries, this publication presents nine principles for utilizing "smart mixes" of regulatory and incentive-based tools (instruments). The following nine principles for smart instrument mixes are explained further in the publication, bolstered by examples and case studies:

1. Ensure compatible instrument combinations

2. Calibrate interventions towards points of least resistance, lowest cost, and maximum impact
3. Sequence or scale interventions as necessary to achieve goals

4. Empower participants to act as surrogate regulators and enable voluntary initiatives

5. Maximize opportunities for net gain outcomes

6. Consider and harness the responsiveness of stakeholders (bottom-up matters)

7. Consider top-down relationships, opportunities, and constraints

8. Monitor and adapt the smart mix in light of its effectiveness

9. Assess performance and adoption of better interventions

ABNJ fisheries are broad in scope and scale, and are composed of heterogeneous States and fishers with varied incomes and motivations. The result is that risks, expected costs, speed of transformation, scale of investments, and returns from these fisheries are highly variable. Thus, the nine principles should not be viewed as prescriptive. Instead, the principles provide guidelines for managers and policy makers to reflect on existing management, and steer stakeholders through an adaptive process to effect change. The biggest takeaway is that there is no single solution or path. Instead, these principles indicate solid directions to proceed, tempered by general conditions found across case studies presented here and in the wider OPP body of knowledge. 


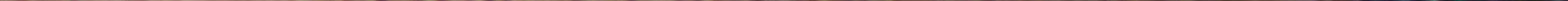




\section{Introduction}

The term "areas beyond national jurisdiction" (ABNJ) describes the areas of the ocean that are not subject to the exclusive jurisdiction of any individual State. It includes both the high seas and the seabed beyond the outer limits of the continental shelf. The management of fisheries in $A B N$ is fundamentally affected by the nature of the resource base and its location, and the wider international governance framework (Barnes 2009).

The management of transboundary fish stocks, especially those in ABNJ, faces a series of challenges (Ardron et al. 2014). ABNJ fisheries are complex and heterogeneous, presenting a number of challenges, as listed in Table 1. Fish stocks form part of a highly complex ecosystem facing negative impacts from overfishing, destructive fishing practices, increased shipping, marine pollution, and potential seabed mining activities. Climate change-induced ocean warming and acidification present additional challenges
(Cochrane et al. 2009). These are compounded by the need to manage the complexities of governance; coordinate and ensure compliance of multiple actors across local, regional, and global levels; and incentivize change towards sustainable resource use (Blanchard 2017).

Since fisheries within ABNJ are not exclusive to any State, States must cooperate to regulate such resources (Barnes 2016). Thus, it is usually more difficult or costly to restrict or manage access to ABNJ resources compared to resources in the exclusive economic zone of one nation. However, the nature of cooperation to manage ABNJ fisheries can have positive spillover effects in member countries with weak governance regimes.

Fish stocks in ABNJ are common pool resources, meaning they are non-excludable, and harvesting remains competitive (Barnes 2009). Excludability may exist to some degree as a product of

Table 1. Management Challenges in ABNJ FisheriesComplexity and Heterogeneity
CHARACTERISTIC
CHALLENGE LEVEL
Multiple Actors: Local, Regional, Global
Freedom of the Sea: Common Pool Resource and Free Riding
Highly Complex and Large Ecosystems
Consensus-Based Decision Making at Regional Fishery
Management Organization (RFMO) Level
High
High
High
Have vs. Have-nots
Medium
Medium
Medium
Rules at Global Level Yet Enforcement Rests with States
Complex International Governance Framework
Low
Data Consistency 
limitations on physical access to the fish stocks and efforts to restrict or condition access under international law. Such excludability is imperfect and dependent to a large extent on the information available to local, national, and regional regulators. Information is also critical for assessing the sustainability of fishing activities linked to catch levels, incidental fishing mortality, and habitat impacts. However, the quality of information systems in ABNJ fisheries varies considerably. The information generated may be coordinated regionally, but there remains no single informational management structure for these fisheries. Typically, information is generated at a range of local, national, and regional levels, often with different objectives and data points.

The complexity of ABNJ fisheries means there is no single blueprint for management, nor is it possible to prescribe fixed roles and functions to State and non-State actors such as non-governmental organizations, independent labeling companies, and fish product importers. Creative solutions that embrace Smart instrument mixes and multiple actors improve upon the effectiveness of more conventional forms of Statecentric regulation.

Fishing activities in areas beyond national jurisdiction are governed principally through controls on flag State vessels (Barnes 2015). These activities may be coordinated through regional fisheries management bodies operating under rules of international law (Rayfuse 2015). Such rules focus on managing the conduct of fishers, but ultimately, the enforcement power belongs to the flag State. States are responsible for the provision of information such as landings, and may have other monitoring, control and surveillance (MCS) obligations.

ABNJ fisheries, and in particular tuna, are highvalue global commodities, and some States are concerned about not receiving a fair share of these benefits (McCauley 2018). The establishment of regional fisheries management organizations (RFMOs) has in some cases established a clearer framework for States with a real interest in a fishery to negotiate with more established fishing nations. While conflicts of interest remain, the introduction of management measures requires consensus-based decisions, meaning that States with diverse interests need to make concessions (McDorman 2005). If the latter is not achieved, the outcome is commonly gridlock in the RFMO process.

The complexity of transboundary fish stocks means there is no single blueprint for management, nor is it possible to prescribe fixed roles and functions to State and non-State actors such as non-governmental organizations, independent labeling companies, and fish product importers. Complicating management further, rules are formed at the regional level through RFMOs, but it is the States that must implement and enforce laws governing the conduct of fishers (Gilman and Kingma 2013). Conflicts arise when such rules are not adopted or enforced by States, or when compliance generates resistance from domestic fleets. Along similar lines, data collection requirements typically rest with the State where the fish are landed, and depend on those States to have adequate and transparent systems in place to document harvests.

No single tool is able to manage complex natural resource systems. Since any regulatory instrument has strengths and weaknesses, a combination of different instruments is required to deliver desired regulatory outcomes (Gunningham and Sinclair 1999). For example, command and control measures are certain and predictable, but often inflexible and inefficient 
(Gunningham and Garbosky 1998). Informationbased measures are often non-intrusive and costeffective, but unreliable when the costs of noncompliance are low. Instrument combinations well suited to complex real-world situations typically result in second best solutions because first best outcomes are not feasible or cost-effective.

To-date the governance of fisheries in ABNJ has presented different mixes of management tools. These mixes may vary at different local, national, regional, and global scales. They may also interact across different management scales (Barnes 2019).

The first principle of good intervention design is to accommodate a range of intervention tools and techniques. This includes international or transnational measures (such as treaties), State-based public regulation (e.g., legislation), tenure/rights-based measures, contracts, and market-based mechanisms, informal (i.e., nonlegal/non-binding) measures, and financial tools (Barnes 2019). These tools need to be able to operate at different geographic scales and address a wide range of actors, from the States to individuals. They also need to be adapted to the different physical characteristics of the target resource base or wider ecosystem. For example, certification schemes that depend only on the actions of one nation may not work for fish stocks in $\mathrm{ABNJ}$ in cases where the actions of other fishers erode sustainability conditions.

Creative solutions must embrace smarter approaches to the governance of resources. Smart instrument mixes are thought to improve upon the effectiveness of more conventional forms of State-centric regulation by combining multiple actors and modes of societal steering (Gunningam and Sinclair 1999). Smart mixes present a pluralist approach for involving multiple public and private forms of control in the hands of public, private, and third-sector bodies. Mixes of public and private instruments are characterized by sequentially flexible and dynamic processes of learning and institutional change. It is claimed that, "In the majority of circumstances, the use of multiple rather than single policy instruments and a broader range of regulatory actors will produce better regulation" (Gunningham and Sinclair 2017). As such, smart mixes of instruments are well suited to the complexities of managing fisheries in ABNJ, with multiple heterogeneous actors and complex global/regional supply chains (Barnes in press).

Our report draws on past performance and the future outlook of innovative incentive-based tools applied towards the development of a theory of change in the reform of highly migratory and transboundary fisheries at the regional and global scales. This can inform deliberations to address project challenges and conceptualize a broader longer-term innovative vision for ABNJ management. In doing so, we develop a set of nine smart mix design principles based on multidisciplinary insights from scholars and practitioners in the area of ABNJ management. Before outlining these principles and the case studies used to support them, we first outline the key drivers of change for incentive-based forms of management intervention. 


\section{Instruments, Interventions, and Drivers of Change}

"Instrument" is a catch-all term for a range of documents or agreements, such as a document of title, lease, permit, contract, legislation, treaty, or soft-law instrument. These include both formally binding and non-binding measures. An intervention could take the form of an instrument, but could also include practices and processes such as the creation and attribution of authority to act, the decision to use one or other of a range of instruments, when to use an instrument, and the use of instruments in a particular way.

Improvements to the management of shared and highly migratory fish stocks can be implemented at different levels (international, regional, national, and local) (Lodge et al. 2007). It can be achieved through a wide range of legal, financial, and economic tools, and combinations thereof (Hahn and Stavins 1991; Grafton et al. 2006). While attention has been given to the application of legal, financial, and economic tools, this has been predominately done in isolation from each other, rather than in "smart" combinations that allow these tools to achieve compliance and reinforce each other.

Incentive-based tools are a range of interventions that change or introduce economic incentives for individual behavior, while allowing the actors to decide how to respond to those incentives (Pascoe et al. 2010). Some innovations can evolve at local levels, the benefits of which are captured by States, NGOs, and industry, and then rolled out in other fisheries (Bailey et al. 2016). Some reform can be driven at higher levels through international and regional agreements, which then influence practices at national and local levels (Barnes 2019). Legal reform can be a means to facilitate the operation of certain incentivebased tools (e.g., transferable quota rights), while establishing better enabling conditions for reform to take place (e.g., security for investors). Incentives may also include financial incentives (e.g., investment), which in turn can directly influence behavior or leverage change by supporting legal or economic initiatives. Evidence shows that any change to management or fisher behavior requires some combination of these approaches.

Incentive-based approaches are dependent on identifying which entity/ies (States, RFMOs, consumers, or fishers) to incentivize (Smith 2012). Defining the incentives into two broad groups, "push" and "pull," highlights mechanisms of how they work (Figure 1).

Pull incentives include market-based instruments that shape demand, based on buyer demand for products that make a credence claim of sustainable or responsibly-produced seafood (Roheim et al. 2018). These instruments include consumer-facing certification schemes, such as the Marine Stewardship Council (MSC) that seek to engage buyer (consumer and retailer) purchasing practices and catch documentation schemes (CDS) and/or traceability requirements (Parkes et al. 2010). Sustainable sourcing commitments or agreements by retailers form a major part of the Sustainable Seafood Movement that can have far-reaching impacts depending on the terms of agreements and geographic span of the retailer (Roheim, 2016).

Push incentives focus directly on the production side of the seafood supply chain. These incentivebased interventions include, but are not limited to, financial incentives (e.g., favorable interest rates on loans with requirements to provide data or adopt other sustainability measures), bycatch 
Figure 1. Push Versus Pull Incentives

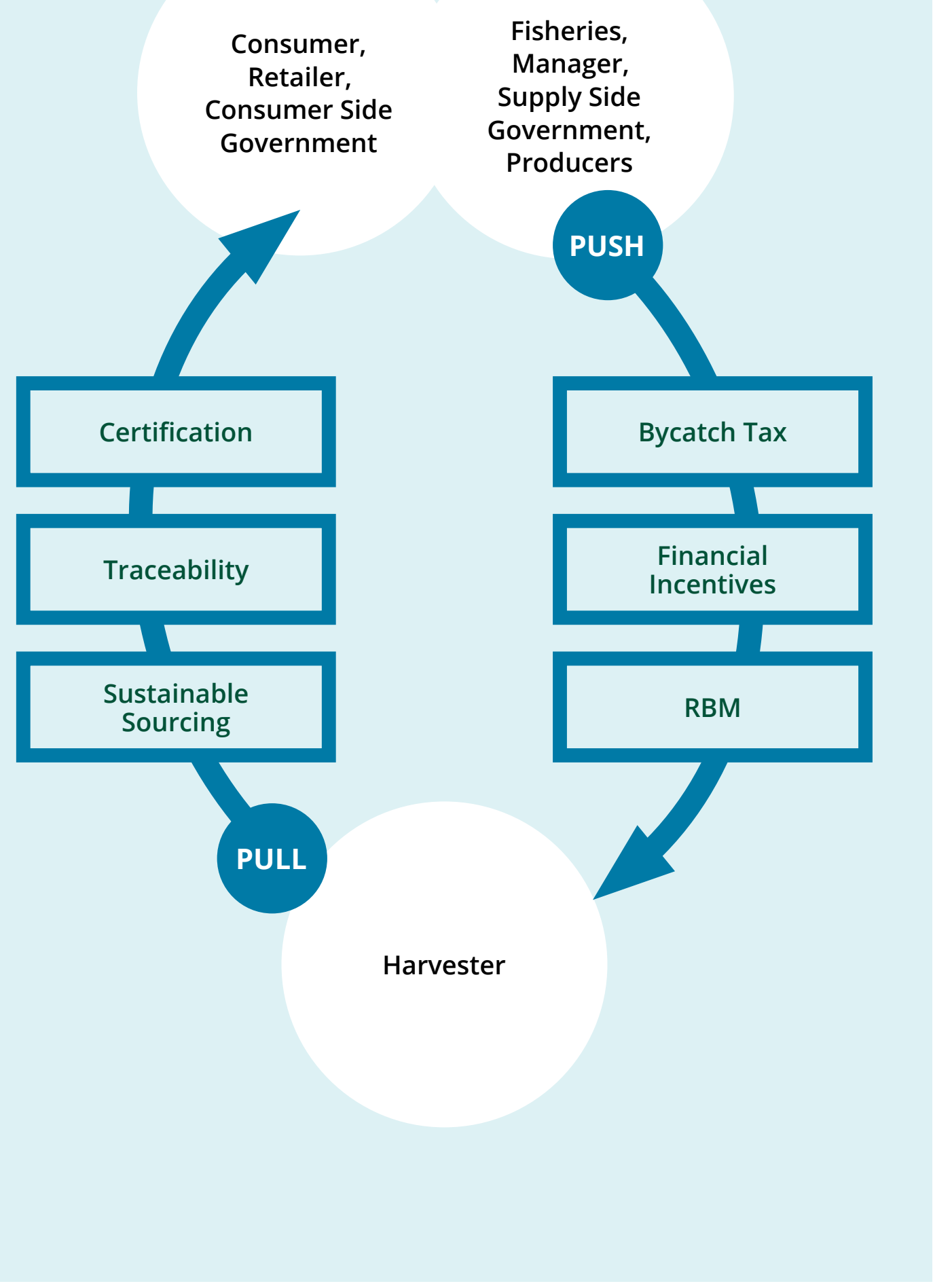


taxes and environmental credit systems, Coasian bargaining, and rights-based management (RBM). These instruments directly impact the operating margin of harvesters and/or the value generated for States leasing access rights. Taxes on bycatch, for instance, increase the cost of catching fish that are discarded, creating an incentive to avoid bycatch. Push incentives are different than pull incentives, but remain related in the sense that they both aim to influence the behavior of producers and/or the formation and enforcement of (State) management and regulation.

There are points within the harvesting and supply chain where interventions can be more effective (Purcell et al. 2017). Effective intervention points are those where changes adopted by a smaller number of influential actors can have wider systemic impacts on the behavior of a wider range of actors up and down the global supply chain. Changes in rules at the global or regional level may influence more actors, but are more difficult to secure due to political and legal barriers. Local interventions may be easier to secure, but may influence fewer actors and practices.

Regional fisheries management bodies can adopt rules that must be implemented by member States. Although this is a highly politicized process (McDorman 2005), RFMOs provide the main opportunity for influencing the conduct of harvesting activities in ABNJ. It is also possible for sub-regional arrangements to influence regional arrangements. The harvesting sector is still quite diffuse and operating under different national legal regimes. However, all catch must be landed and port States can impose controls on landings. This means major entry points to markets or processing facilities are potential locations where change can be leveraged on downstream harvesting activities. Port States can also add import health, safety, and sustainability requirements to their import stream, as can large retailing chains. Consumer preferences can influence practices in the supply chain, including processing and harvest sectors. While consumers operate within widely varying markets, it is possible to influence behavior through high profile or common marketing practices, such as certification and product labeling schemes. Focused campaigns by NGOs and industry champions can help leverage interventions (Jacquet and Pauly 2007).

Interventions cost money and financing can be used for a range of purposes. Several investment formats and strategies are available (Table 2). However, their potential application is not very well known or understood due in part to the emerging nature of private financial investment in fisheries. Financing can be used to support general business incubation or to fill credit gaps using debt. This is important in transitional fisheries (e.g., moving to RBM where quotas are auctioned) or fisheries facing short-term external challenges. Investors can take ownership of fisheries through purchase of assets (including quotas), and then lease fishing options back to fishers. Investment can be used to support sustainable sourcing and certification (e.g., Sea

Incentives affect fishers directly across jurisdictions where international legal instruments are weak or non-existent. Incentives can affect cooperation of States and/or fleets in RFMO or subregional management in ways that supersede legal instruments. These are the strongest arguments for moving towards incentive-based mechanisms in $\mathrm{ABNJ} /$ transboundary fisheries. 
Change Investment Fund), either directly or through leveraging further financial support from private equity. Equity investments can be secured over the longer term by locking sustainable practices into conservation covenants (contractual arrangements linked to the assets). However, the key requirements of security of rights, a sustainable and profitable resource base, and general regulatory capacity remain critical (Barnes 2018).

Successful initiatives often combine or layer different sources of investment (EDF 2018), and can add value by drawing upon investor expertise and support in business plan development. This is important, as investment packages involving multiple or sequenced investments can be structured with pathways for novel or challenging environments. Such approaches can utilize investors open to high risk (e.g., philanthropic groups seeking to stimulate social or ecological improvements) for one part of the fisheries transformation process to generate data, clarity, and security for more risk-averse investors or investors that focus on financial returns (e.g., private equity, banks). It is important that guarantors have a strong credit rating given the critical role they may have in underwriting more risky or innovative investments in fisheries.

Incentives affect fishers directly across jurisdictions where international legal instruments are weak or non-existent. Incentives can affect cooperation of States and/or fleets in RFMO or sub-regional management in ways that supersede legal instruments. These are the strongest arguments for moving towards incentive-based mechanisms in ABNJ/transboundary fisheries.

Given the highly contextual nature of management, any advice on developing and/or applying individual or combinations of incentive- based tools needs to be informed by clear, functional, and regulatory design principles (Barnes 2019). These principles are parameters or criteria that policy makers and managers can use to determine the potential success and effectiveness of any given management tool or combination of tools.

The following smart mix design principles are advanced as a way of guiding decision-makers through the challenge of framing and evaluating interventions. The range of incentive-based mechanisms provides a good toolbox, but none of these tools is likely to work alone. Practitioners need to think about how smart mixes of these instruments can be created to effect change in fisheries by focusing on producers, states, and/ or other key actors that influence production and the establishment and enforcement of rules over fishers. These design principles are drawn from smart regulatory theory, and provide a point of reference for fisheries managers or regulators seeking to enhance incentive structures and regulatory regimes. The point here is not to prescribe the smart mix. Instead, the practitioner is encouraged to engage with smart mixes, and use a set of principles that can guide what mix is needed and how it can, in fact, be smart. The following smart mix design principles and case studies provide a toolkit for decision-makers to work with when trying to develop and evaluate potential interventions in current fisheries management arrangements. 
Table 2. Financing Options Available for Capture Fisheries

\begin{tabular}{|c|c|c|c|c|}
\hline & FOUNDATIONS & GOVERNMENT/PUBLIC & BLENDED INVESTORS & COMMERCIAL \\
\hline Grants & $\begin{array}{l}\text { Grants for: } \\
\text { - Seeding new } \\
\text { concepts } \\
\text { - Programs } \\
\text { - Technical Assistance } \\
\text { - Asset Purchase } \\
\text { - Operations }\end{array}$ & $\begin{array}{l}\text { State/federal/local grants } \\
\text { Gear rebates } \\
\text { Vessel buybacks } \\
\text { New market tax credits }\end{array}$ & $\begin{array}{l}\text { Sometimes provided } \\
\text { alongside a debt or } \\
\text { equity investment }\end{array}$ & Generally not applicable \\
\hline Debt & $\begin{array}{l}\text { Program-related } \\
\text { investments (PRIs) } \\
\text { Impact loans }\end{array}$ & Small business loans & $\begin{array}{l}\text { Public- Private } \\
\text { Partnership (PPP) } \\
\text { Community } \\
\text { Development Financial } \\
\text { Institutions }\end{array}$ & $\begin{array}{l}\text { Bank Loans: } \\
\text { - Recourse or non- } \\
\text { recourse } \\
\text { - Bridge, short-term, or } \\
\text { long- term }\end{array}$ \\
\hline Equity & $\begin{array}{l}\text { Mission- related } \\
\text { investments } \\
\text { Endowments } \\
\text { Structured PRIs }\end{array}$ & $\begin{array}{l}\text { World Bank social equity } \\
\text { portfolios }\end{array}$ & $\begin{array}{l}\text { Social Investors } \\
\text { Social Venture Capital } \\
\text { Funds } \\
\text { Social impact bond }\end{array}$ & $\begin{array}{l}\text { Angel Investors } \\
\text { Venture Capital/Private } \\
\text { Equity } \\
\text { Tax-Equity Investors }\end{array}$ \\
\hline Guarantees & $\begin{array}{l}\text { Underwriting facility } \\
\text { (full or partial) }\end{array}$ & $\begin{array}{l}\text { Domestic investment } \\
\text { underwriting (e.g., USAID) } \\
\text { Bilateral and Multilateral } \\
\text { development finance } \\
\text { institutions } \\
\text { Multilateral investment } \\
\text { guarantee }\end{array}$ & $\begin{array}{l}\text { May be provided as } \\
\text { part of an investment } \\
\text { package }\end{array}$ & Generally not applicable \\
\hline
\end{tabular}




\section{Principle 1: Ensure Compatible Instrument Combinations}

Policy makers should seek to develop the most effective mix of interventions rather than maximizing the size of the toolkit. This requires an understanding of the scope, effect, potential, and limits of different instruments and of their interactions. Not all instruments are compatible with each other or with underlying socio-political and economic systems. Instruments have different degrees of compatibility with each other, and this may generate conflict or contribute to overfishing. For example, the introduction of minimum size limits in a fishery without additional controls on fishing effort could increase mortality through excessive discarding.

Some instruments cannot exist without others, or will be significantly restricted in their scope of application. For example, financial incentives are strongly influenced by the general regulatory conditions within a fishery, and may be stimulated through introduction or strengthening of tenure rights. Case Study 1 (Appendix) provides a good example of why the complementarity of interventions is required to attract and extract long-term benefits from private investment. Here the focus is on solving the excess fleet capacity issue that exacerbates the race to fish and erodes incentives to conserve resources. In many fisheries, capacity reduction has been done through State funding initiatives (e.g., European Maritime and Fisheries Fund). However, if there is security in the fishery, the removal or transfer of capacity could be driven by private investment, or combinations of public and private investment. Typically, security can take the form of secure tenure rights, catch limits, and robust monitoring and enforcement capacity.
In 2014, an International Seafood Sustainability Foundation (ISSF)-led expert workshop on capacity transfer explored the conditions for a successful investment environment (ISSF 2014). If these conditions do not exist at the onset or after transformation, it is unlikely that private investors will provide resources due to uncertainty of repayment. This speaks directly to the need for instrument mixes that contain the correct, or compatible, instrument combinations to reach the goal of privately financed capacity reductions.

\section{Some instruments cannot exist without others, or will be significantly restricted in their scope of application. For example, financial incentives are strongly influenced by the general regulatory conditions within a fishery, and may be stimulated through introduction or strengthening of tenure rights. Case Study 1 (Appendix) provides a good example of why the complementarity of interventions is required to attract and extract long- term benefits from private investment.}

Certain legal and non-legal instruments and processes form an essential part of the mix of tools governing high seas fisheries. The various international laws represent the umbrella under which compatible instrument combinations must be made at the regional and then national levels. They establish basic legal, market, or 
financial capabilities, and enable cooperation or transactions between States. They enable other instruments to be put in place, and they ensure that all stakeholders and affected subject matter are factored into the management of the resources base.

Cutting across these governance levels are a range of financial and market-based instruments. Some tools are implemented and actively used by the State. Others are facilitated by the State and used by private actors. This may allow for regulatory efficiencies by permitting regulators to focus their limited resources accordingly. These generally depend upon good governance, and a certain degree of management infrastructure capable of developing, implementing, and enforcing harvest control rules (Barnes 2018).
What is critical is to understand the enabling conditions that affect these efforts.

Too many instruments in the mix can also cause complexity or regulatory overload. This is often the case in traditional command-andcontrol regimes in which regulatory growth is a response to regulatory slide. Such a situation can increase management costs considerably without the corresponding benefits, and lead to gridlock during RFMO negotiations. Therefore, it is critical to focus on complementary instrument mixes. Identifying the best mix of instruments is difficult and may likely emerge only over time through an iterative process. It will be determined contextually, and in light of the other design principles below.

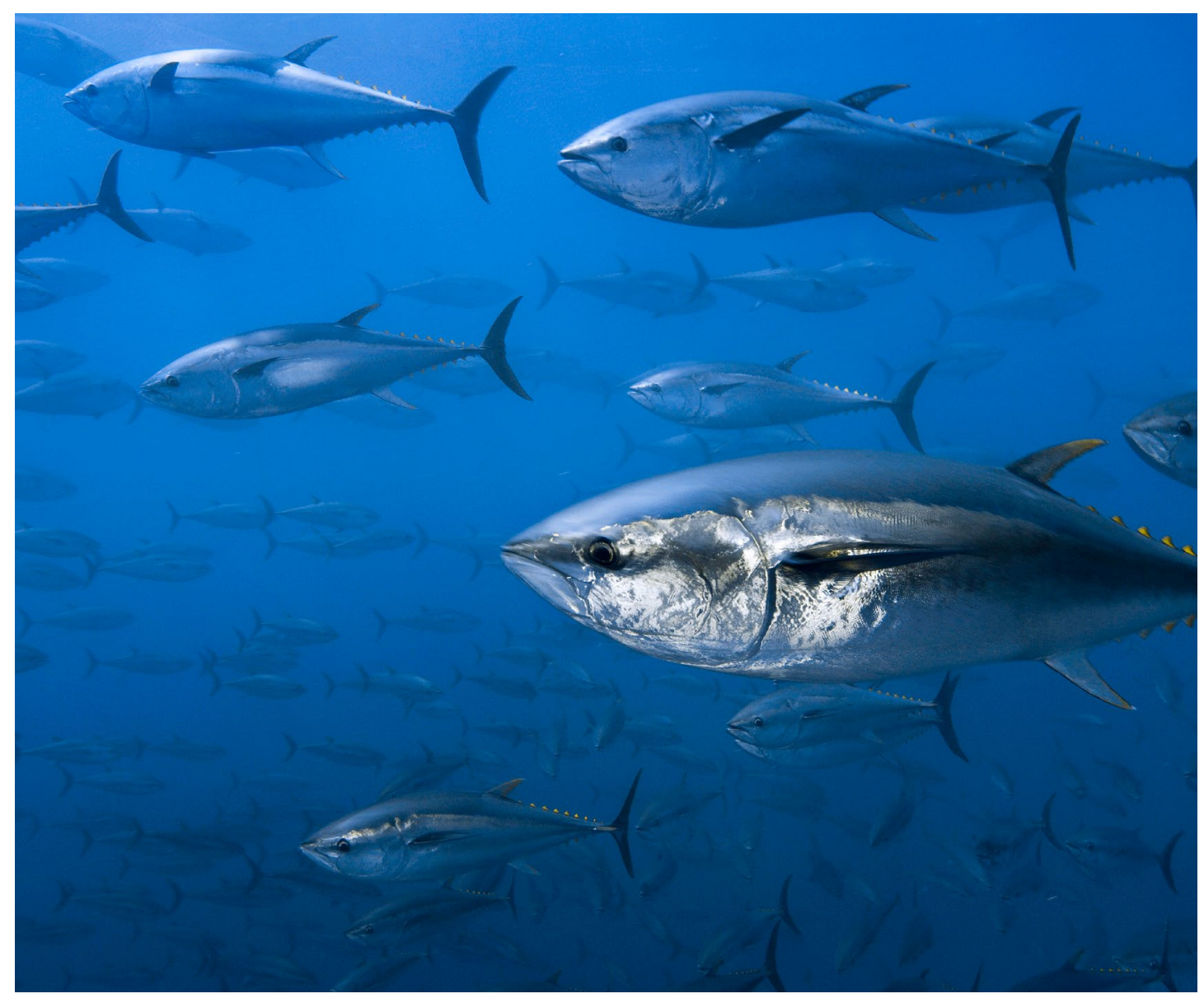




\section{Principle 2: Calibrate Interventions Towards Points of Least Resistance, Lowest Cost, and Maximum Impact}

While incentive-compatible instruments are preferred, sometimes regulatory interventions are needed. Regulatory interventions can be prescriptive (setting the rules of the game) and coercive (ensuring the rules are followed). Not all interventions will have the same impact. As a general rule, the least-cost, least-conflict, and targeted measures should be preferred in the smart mix (Gunningham and Sinclair 1999). Regulators have finite resources and capacity, so they must target interventions at points where they will be most effective. Assuming the same outcomes are possible from different kinds of interventions, targeted, least-cost, low-conflict options are preferred. On the other hand, combinations of regulations should not lead to more cost or conflict or be overly broad, and the smart mix design needs to balance these concepts simultaneously.

\section{Low-Cost Interventions}

Regulation and other interventions can be expensive (Hahn 1998, Nielsen 2003). All forms of prescriptive intervention through public regulation entail human and capital costs associated with researching, designing, and progressing regulations through legislatures (Arnason 2009). Once adopted, interventions may have continuing monitoring, compliance, and enforcement costs to be borne by the State or other entities. Highly coercive measures are likely to be expensive because they require administrative resources for monitoring or policing. The cost of intervention will also depend upon the level of intervention. Local interventions, targeting a smaller number of actors, will generate lower transaction costs than interventions at the global scale. For example, negotiating a global agreement to curtail harmful fishing practices entails higher transaction costs than a regional or sub-regional agreement because of the number of parties and diversity of interests to be accommodated (Libecap 2014).

The Parties to the Nauru Agreement (PNA) vessel day scheme (VDS) (Case Study 4 in the Appendix) is a good example of a low-cost intervention. The first best right would have been a catch right assigned to individual vessels. However, at the onset of the program, the VDS was designed as an access right assigned to member countries, as it was more cost-effective to monitor days at sea compared to vessel level catches.

\section{Low-Conflict Interventions}

Less interventionist measures may produce less resistance from participants in tuna fisheries because they do not challenge the authority of those actors, whether individuals, companies, or States. Less interventionist measures may be perceived as more legitimate because they do not infringe upon individual autonomy. Interventions that are less challenging and perceived as more legitimate can enable quicker decision-making and response to environmental or market circumstances (Jentoft 2000). Enhancing information can be regarded as a low-level intervention and a precursor to stronger and targeted interventions, particularly when enhancing information that engages stakeholders. 
Interventions that are designed through

engagement with stakeholders and/or are combined with incentives to reduce short-term losses could reduce conflict due to familiarity and "buy-in" from affected fishers. Case Study 2 (Appendix) details the use of a rapid assessment tool, the Fishery Performance Indicators (FPI) developed by Anderson et al. (2015) that, while not specifically a stakeholder engagement tool, can be utilized in that fashion. When FPIs are used as the first stage of a larger, more holistic fishery development project design, as in the Caribbean OPP project, they can become the platform for data collection, financial modeling, stakeholder engagement, and ultimately the design of the entire intervention package. Gentner et al. (2018) detail this entire process, from FPI to completed business case, that illustrates the utility of the FPIs as a low-conflict intervention tool in Grenada and the Dominican Republic.

\section{Targeted Interventions}

An intervention strategy is fundamentally underpinned by research and information about the state of the resource, the actors, and institutions, including market and consumer expectations. ABNJ fisheries are more complicated, as they support a global industry operating within a global governance framework with variations at regional and national levels. The governance structures cover all elements of the supply chain from "hook to plate," encompassing pre-catch management, harvesting, landing, processing, supply chains, marketing, and consumer protection (Figure 2). Levels of compliance will vary between different sectors of the fishing industry within the fishing sector, and even within the same sector (Sutinen et al. 1990; Hatcher et al. 2000). There may be sectors that lag behind, refuse to comply, or remain indifferent to interventions for social, cultural, economic, or political reasons.
An understanding of how each ABNJ system operates will be required to identify optimum intervention points, which in turn may determine the choice of intervention(s). Intervention points will rely on how interventions interact with each other under international legal frameworks and links in the supply (Figure 2). For example, the rights conveyed post-harvest lend the security necessary to pass incentives to the actors in the supply chains to impact behavior. Finance, investment, and capacity building work up from the bottom through the various entities and organizations to finance interventions. Each node in Figure 2 is a potential entry point for developing the smart mix of incentives and regulation to reform the management of ABNJ fisheries. The job of initial assessment and project development is to identify nodes that can be feasibly targeted to effectively address major problems in the fishery.

Case Study 3, in the Appendix, details the impacts of targeting key actors in the value chain. A study by Bailey et al. (2016) investigated the influence of key actors in the value chain for tuna in South East Asia in order to identify engagement points for fishery interventions (certification schemes) that will produce equitable benefits. In South East Asia, "middlemen" play a key role in fish trading and in providing fishers with access to capital, infrastructure, and other services. This control may result in market benefits not accruing to primary producers who improve sustainability practices in certified fisheries. Recognizing this potential problem, the introduction of certification schemes was designed to facilitate a reorganization of value chain structure in the fishery that also changed fishermen's perceptions of the resource and the market. This is an example of looking at multiple aspects of a project holistically to reduce cost, reduce conflict, and target interventions. If the middleman connection had been ignored, it is unlikely that the certification scheme would have been successful at meeting all objectives. 
Figure 2. Overview of ABNJ Fisheries Value Chains as they Relate to Intervention Nodes.

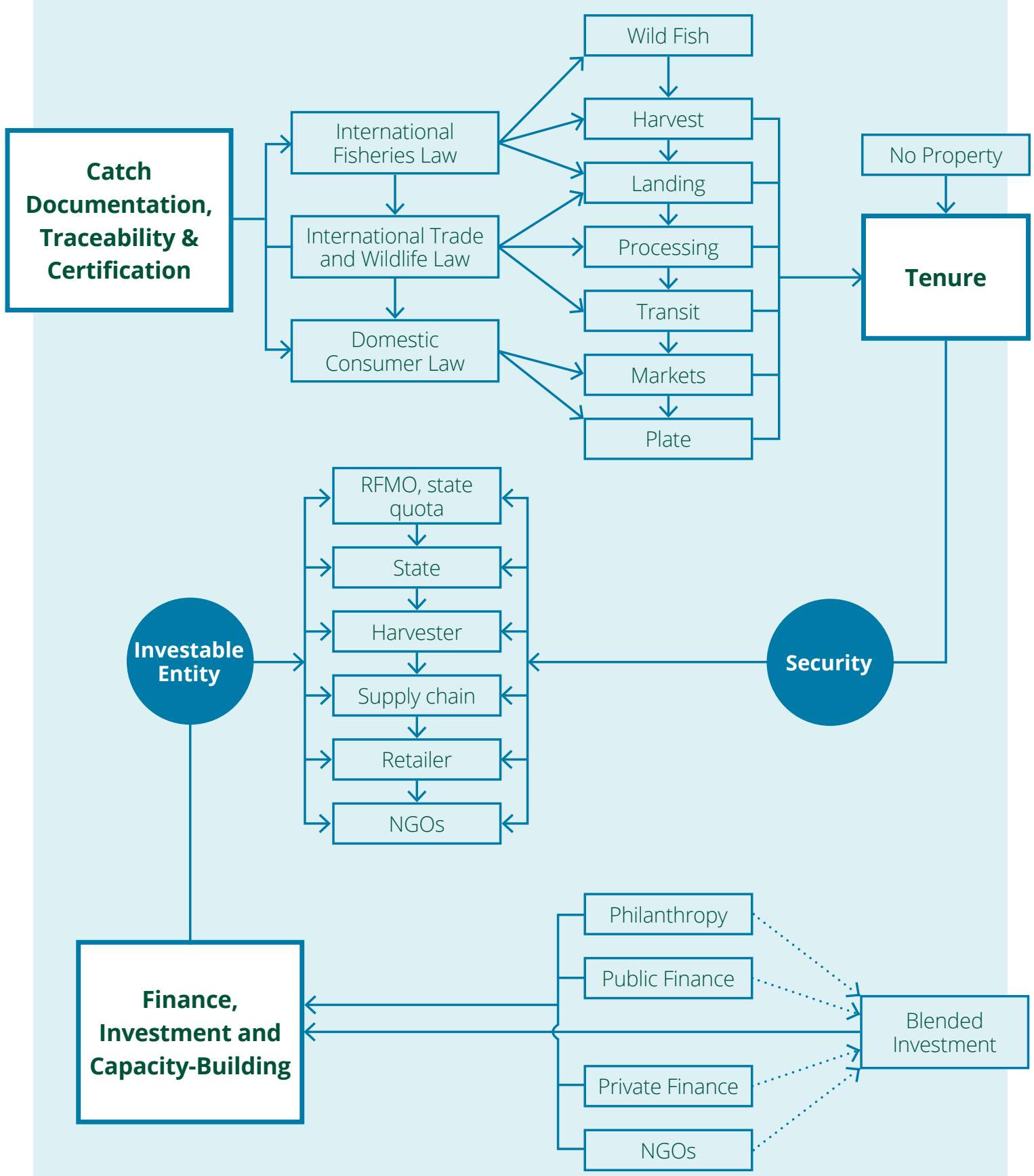

Key:

$\rightarrow$ Each arrow on this figure is an entry point for either an instrument or an intervention. 


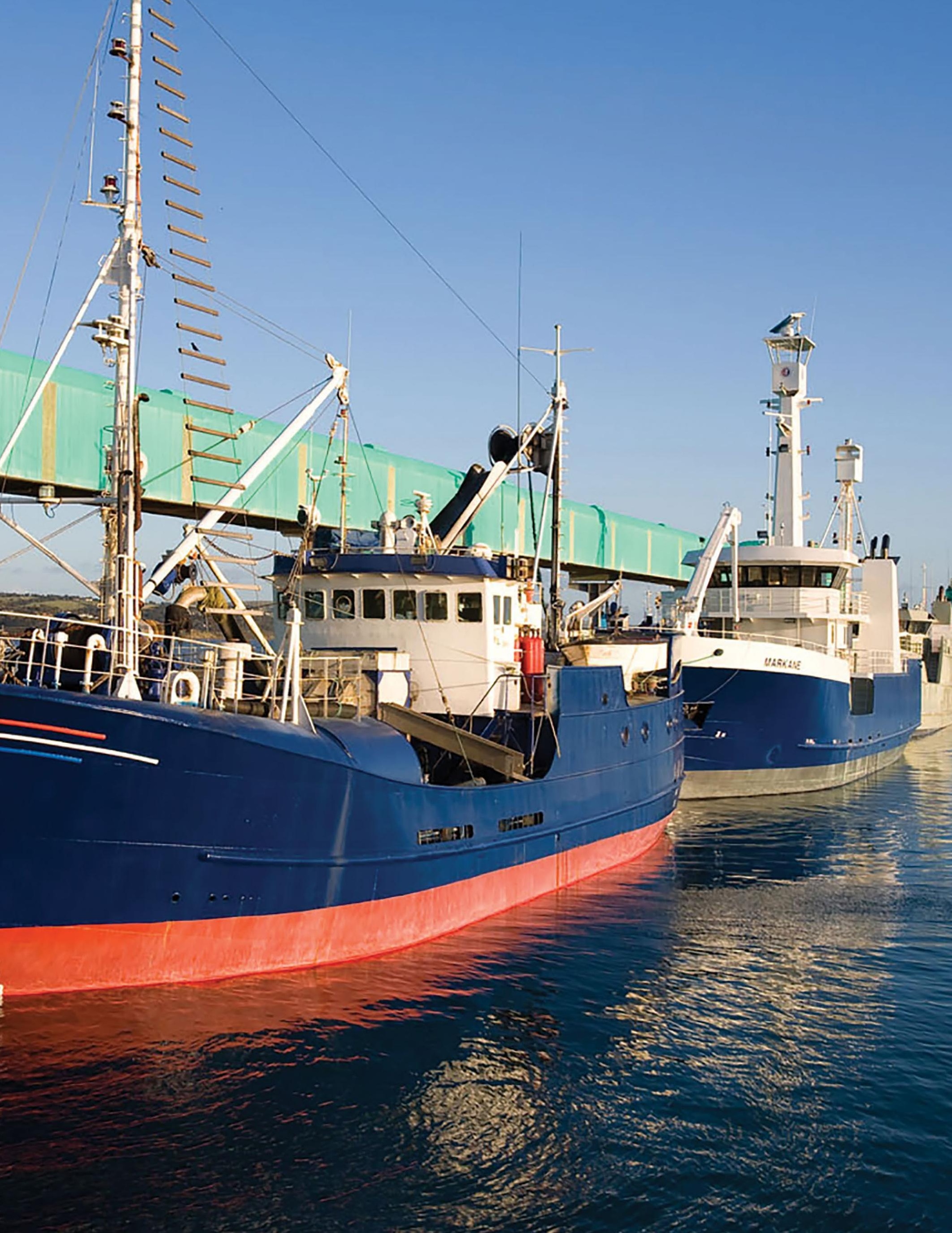




\section{Principle 3: Sequence or Scale Interventions as Necessary to Achieve Goals}

Given the complexity in ABNJ fisheries, it is especially important to consider adoption of a scaled or sequenced approach to interventions (Gunningham and Sinclair 2017; van Gossum et al. 2010). Sequencing may form part of a program of reform and/or part of a general regulatory strategy. Prior to implementation, a pathway to reform should identify a series of steps to be taken to achieve a longer-term goal and important milestones at shorter time intervals to identify shorter-term success. Development of this logic model begins with an assessment of the current situation that identifies gaps, mapping of stakeholders, and outreach and education. The design of interventions will need to suit context and needs, and leave room for adaptations. Adaptation plays an important role in sequencing and scaling.

Case Study 4, in the Appendix, provides a perfect example of an adaptive sequence of interventions over a long period needed to reach the ultimate goal of fishery rationalization. The PNA VDS is the result of a process that started in the early '80s to secure the fishing rights in the exclusive economic zones (EEZs) of small islands, increase the fishery rents generated by granting access to foreign fleets, and improve livelihoods in Pacific island nations. It began with an agreement to cap vessel numbers. When that did not result in increased revenue, PNA issued licenses that restricted foreign vessels to landing locally, provisioning locally, and using local labor. These new measures did not result in the desired increases in rents or improvements in local economic conditions. Furthermore, fleet capacity increased even further, resulting in further increases in capacity.
The VDS was the next step in this process. The PNA capped total effort, eliminated limited entry, and created demand for days across users. Through allowing transfer of the limited effort, rents began to increase and harvests came under control. While the system is still evolving, initial performance assessments are favorable.

Sequenced interventions identify a range of alternative interventions (sometimes by different actors) that can be used alone or in combination with others to encourage compliance. They can be at the same or different scales. Scaled interventions may start with voluntary/cooperative measures before becoming progressively more punitive or coercive. Up-scaling could be internal to an instrument (e.g., increasing level of fines for infringements) or introduce new, increasingly more coercive measures (e.g., sanctions for failing to switch on remote observation systems or obscuring their use). Upscaling could also result from expansion of interventions across different sectors in a fishery.

The design and availability of sequenced and scaled interventions can positively influence cooperation and compliance at earlier or lower stages (Guzman 2002; Nielsen 2003). For example, the threat of serious interventions (regulatory controls, sanctions) may encourage actors to design and comply with self-regulatory measures.

To be effective, the scaling or sequencing of interventions must be signaled to industry. Principles, tools, and techniques of good fisheries management are located in non-legally binding instruments, rather than binding agreements. 
This can be a step towards consolidating stronger governance frameworks. As regards compliance, it is common for States to prioritize and pursue diplomatic settlements in order to avoid compulsory third-party dispute settlement.

In some circumstances, scaling may not be appropriate-e.g., responding to crises (Khan et al. 2018). Here the urgency of the situation may require quick, comprehensive, and unequivocal action. This normally requires regulatory intervention (e.g., an emergency moratorium on fishing following a stock collapse).

Interventions need not be limited to restrictive or punitive measures. They can accommodate positive interventions that can facilitate compliance (Hanich et al. 2008); for example, capacity-building measures to improve skills (Hanich et al. 2008) or financial assistance to stimulate new practices (Encourage Capital 2016).
Interventions will change attitudes of stakeholders and institutions over time (Cunninham et 2009). As part of an iterative, adaptive approach, interventions may be scaled up or down or restructured over time as patterns of noncompliance change (Hilborn and Sibert 2009). For example, initial efforts to address illegal unreported and unregulated (IUU) fishing through non-binding instruments have evolved into binding instruments because levels of IUU fishing remained high. 


\section{Principle 4: Empower Participants Best Able to Act as Surrogate Regulators and Enable Voluntary Initiatives}

This principle seeks to empower the right mix of decision-makers to ensure that the decisionmaking authority rests in the right place (Gunningham and Sinclair 1999; Boström 2015). The State (through its legislature or fisheries administration) is normally best positioned to initiate interventions. Yet it is not the only actor capable of influencing or initiating change in the management of fisheries. Other actors can and have influenced and improved fisheries management. Such actors are referred to as "surrogate regulators" (Hatanaka and Busch 2008) and can include other States, companies (using self-regulation and market-based measures), nongovernmental organizations, consumer groups, industry interest groups, fishers, or communities of fishers.

Sometimes, surrogate regulation occurs spontaneously; for example, the determination of fishing practices within a family of communitybased organizations. Long-standing community tenure relationships in Japan and other regions are good examples of the devolution of regulatory authority to communities through co-management. However, certain regulatory outcomes, such as changing allocations of fishing rights across States or setting overall catch and effort limits for a fishery, are unlikely to happen voluntarily (Gunningham and Rees 1997). There are two ways to empower surrogate regulators: through delegated legal power and/or by influencing the regulatory process.

\section{Delegated Legal Power}

Non-State actors can be empowered to act through delegated legal power (Gunningham 2009). An example of this might be the legal authority of an industry group to decide how fishing quotas are allocated among its members. This occurs in many fisheries, where "producer organizations" manage commercial fishing opportunities of its members, or in the case of community development quotas, such as in Alaska (Hatcher 1997). Other examples of delegating legal power include allowing third parties to report IUU activities for action in legal proceedings and allowing private parties to provide capacity building through training and support services.

Case Study 4 details the PNA/Pacifical implementation of another vehicle, joint ventures, to create surrogate regulators (Appendix). The PNA wanted to place pressure on the industry to provide skipjack tuna produced with lower by-catch of bigeye and yellowfin tuna. To generate this incentive, the PNA sought to certify free school purse seine sets under the MSC certification process. In order to generate a financial incentive, the PNA entered into a joint venture with Pacifical, delegating the promotion and marketing of MSC certified skipjack tuna to Pacifical. Pacifical would guarantee a certain premium to both the fishermen and canneries if they could verifiably follow the certification label rules. Control in the fishery has been increased in two dimensions. First, the certification reinforces the 100 percent observer coverage rule, ensuring 
the fishery lives up to the bycatch reduction. Second, the program has increased transparency and traceability.

\section{Influencing the Regulatory Process}

Non-State regulators can be designed into management regimes by having their capacity to act or influence behavior recognized as a factor in a regulatory process (Bush and Oosterveer 2015). This can be done in varying degrees. For example, at a minimal level, the provision of adequate information can stimulate responsive action (self-regulation) from an industry. This includes the setting of standards for sanitation and data collection/information systems. Industry- or non-governmental organization (NGO)-led fishery improvement projects (FIP) and certifications are another example of designing empowerment into interventions. Certifications in tuna fisheries often start with a FIP. FIPs are often owned by non-State stakeholders who apply pressure to the State, supply chain actors, and harvesters to achieve management goals that will allow certification.
Case Study 5, in the Appendix, gives more details on certification schemes.

FIPs and certifications can be used to determine risks and liabilities, and so feed into commercial initiatives, e.g., insurance or investment (Bush et al. 2017). Information mechanisms can be intensified. For example, a fisheries management regime based upon scientific advice can stimulate and accommodate the provision of technical advice from a range of agencies. If the advice is used to determine regulatory parameters (such as the setting of the total catch, or designation of a closed area), information providers can influence regulatory behavior.

Another example is the creation of a system of tradable quotas (Havice 2013). Here, private parties, through market mechanisms, become de facto responsible to determine how quotas are allocated. More intensive input can be stimulated by the provision of funding and support to third parties, or the direct designation of industry groups as self-regulators. Here, investment

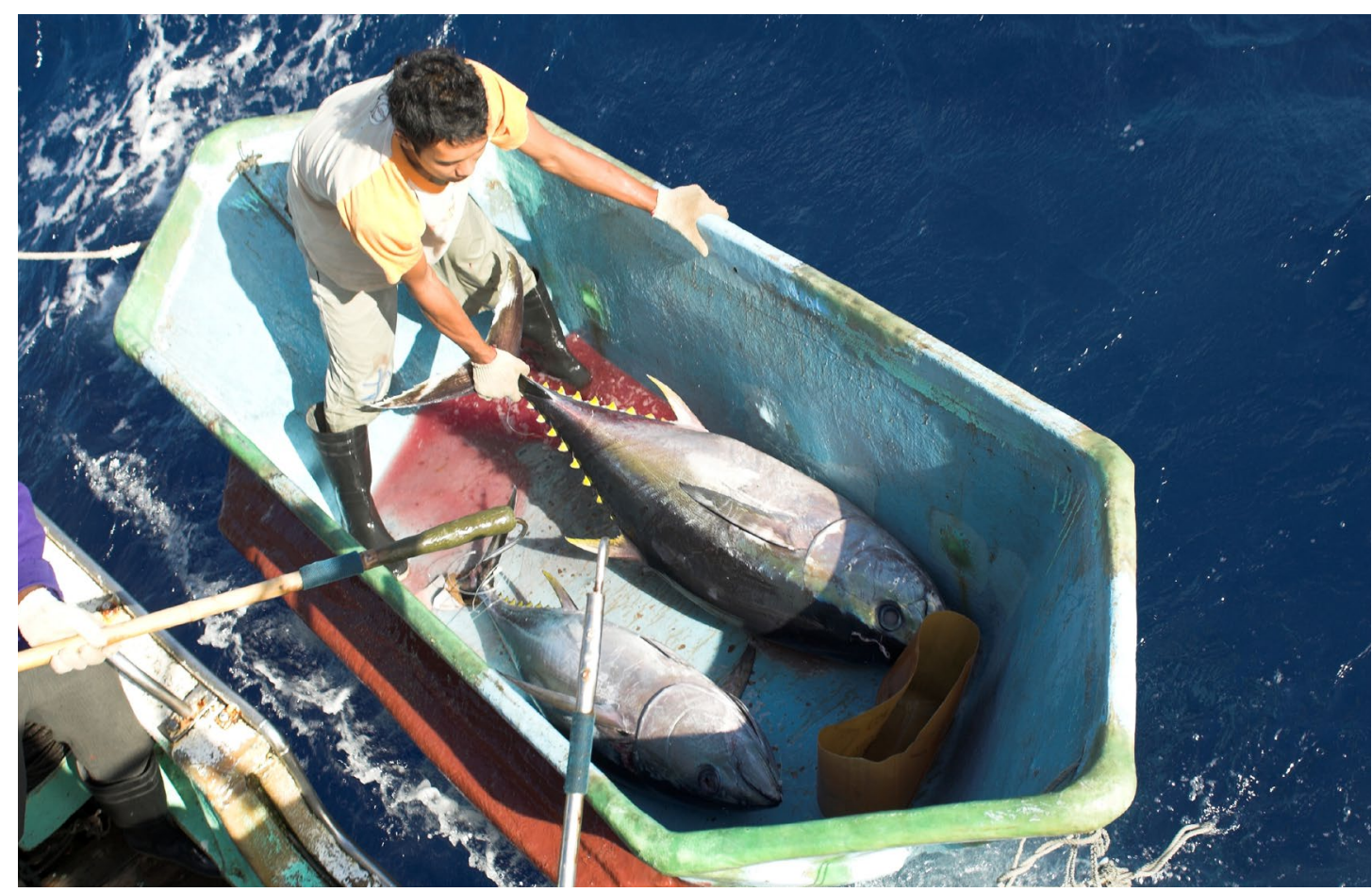


groups can use financial incentives to leverage change in parts of the value chain.

Case Study 6, in the Appendix, offers an example of non-State regulators being designed into management regimes by placing restrictions on investments. The "ISDA strategy" for the Philippines tuna fisheries advocates funding the provision of vessel monitoring systems (VMS) and support for a CDS, which can be used to reduce IUU fishing. These types of investments do not guarantee improved fish stocks, but instead act as a catalyst to regulatory change that could have stock impacts. Such changes could be introduced without outside capital, but this injection of funding can overcome political or economic barriers to change. Other public/ private partnership investments can be targeted at improving supply chain infrastructure such as gear improvements to reduce bycatch or improve catch handling and storage.

States can also empower surrogate regulators by recognizing the value of codes and guidelines from third parties, such as fisheries good practices guides (FAO Code of Conduct for Responsible Fisheries and the BSI Code on due diligence in establishing the legal origin of seafood products and marine ingredients).

Regional fisheries management organizations can be viewed as a form of surrogate regulator in the sense that they collectively exercise/coordinate the original legal authority of members to manage fishing activities of their flag ships. That is, the direct power to regulate resides only with the States. The power of an RFMO, or sub-regional fisheries arrangements such as the PNA, is limited to that authority granted by the founding member States in its constituent treaty. As a result, RFMOs have very little ability to regulate directly, beyond setting the allocation of fish stocks or, in some cases, effort or capacity caps. Once those goals are set, it is up to States, to actually formulate direct measures. States can then empower
non-State actors to act as surrogate regulators, but that is at the discretion of the State. At the international level, surrogate regulators are best accommodated through indirect means, acting through the State process or through industry initiatives enabled by the State.

There are four reasons that empowering surrogate actors is important in fisheries management. First, empowering stakeholders in the regulatory process may encourage compliance. For example, fishers may be more willing to accept gear restrictions or rights that they have helped design (Pomeroy 1995). Second, surrogate regulators may be able to reach actors that the State cannot, either because it is unaware of the identity of actors or because they are simply too diffuse to target through regulation (McClanahan 2009). Third, State resources are limited, even in wealthy States. As such, regulatory efforts must be carefully targeted. By empowering surrogate regulators, the State enhances its regulatory reach. This may allow the State to target limited resources for critical issues upon which there is no alternative to public regulation. Finally, some private actors may be far more influential than States. For example, a lending agency that imposes terms on its loan or threatens to foreclose on the loan may have more immediate and effective control over the conduct of the borrower. Private contracts, through standards set by an importer, can elicit more responsive behavior compared to legal regulations.

Empowering surrogate regulators does not free the fisheries administration of its responsibilities because intervention may still be required to stimulate or ensure the surrogate regulator acts in accordance with policy rather than commercial interest or self-interest. For example, a financial agency may require direction or stimulus to impose environmental conditions upon a loan, or it may require the provision of information to help it assess the conduct of the borrower. It may 


\section{Principle 5: Maximize opportunities for net gain outcomes}

Any regulatory interventions should stimulate or create opportunities for net gain outcomes (Gunningham and Sinclair 1999). While win/win is an over-used statement that generally cannot be achieved often, the heart of this principle is to search instead for balancing gains against losses. Principle five also entails structuring individual decision making, or (in social science terms) enabling individuals to act.

Interventions should stimulate the "right" choices by fishers and other key stakeholders (Bladon et al. 2016). Interventions should incorporate the social or relational conditions that enable fishers to make decisions producing triple bottom-line outcomes. At one level, this may be simply about creating full awareness of the costs and benefits of different regulatory outcomes. Incentives may go beyond engendering basic environmental standards by enhancing corporate branding and position, opening up new markets, improving product quality, and fostering positive consumer relationships. They may also result in the removal or reduction of the risk of legal liabilities. Further, creating opportunities to exceed basic standards might stimulate new technologies and opportunities. However, some of these interventions come with near-term costs and, to be successful, may require that losers must be compensated by winners.

Most studies only engage single tools, regulations, or mechanisms when looking at effecting change through incentive-based interventions (ITQS, TURFs, or certification). These are all presumed to work through the bounded rationality of individual actors. But this principle stands to make the point that when multiple instruments are in play, we need to understand the interaction between these rationalities (Muradian 2013). Are they the same for each instrument or not? And, returning to structure, what are the social conditions/ relations that enable or hinder individuals to respond to these multiple instruments in a way that produces the desired outcomes?

\section{Interventions should incorporate the social or relational conditions that enable fishers to make decisions producing triple bottom-line outcomes. At one level, this may be simply about creating full awareness of the costs and benefits of different regulatory outcomes.}

Even if the benefits are known by participants in a fishery or supply chain, the state of the domestic, regional regulatory environments may fail to incentivize firms or individuals to adapt their fishing practices to improve environmental impacts or sustainability. This may be in part due to the motives of fishers. Here, obstacles to change include "bounded rationality" (limited knowledge or ability to formulate a pathway 
to change behavior) or a focus on short-term rather than long-term benefits. It may also be due to limitations in the structure of the fisheries management system. For example, there may be institutional barriers or choke points that prevent private actors from taking action. For example, in fisheries, disagreements about benefit distribution or vetoes may impede the adoption of rights-based entitlements. In both instances, the market alone cannot deliver changes. This means regulators have a role to play in removing regulatory obstacles, and stimulating improved performance when bounded rationality exists or when the short-term costs outweigh longer terms gains.

Interventions may take many forms: education, training, capacity building, legal reforms, or other paths. A challenge is to assess the potential behavioural impacts of any intervention, as each type of intervention impacts different actors in different ways. For example, some fishers may respond to profit-related incentives, whereas others may respond to social or community benefits.

Regulators can design cost and accounting systems that accommodate a fuller range of environmental costs. If industry is aware of the costs and benefits, it can be encouraged to adapt its behavior (Arnason et al. 2000). The administrative costs and benefits in a fisheries management system (e.g., preferential allocation of quotas, differential level of license fees and quota prices) could be adapted to reward fishers that go beyond minimal standards (e.g., inclusion of all catch against landing quota). For example, a fisher using certain gear could receive licenses at reduced rates. Managers can also adopt programs that motivate actors onto a greener track.
Further increasing the level of intervention, States or fisheries managers can set targets or goals private actors must achieve that will result in a net positive benefit. For example, a management authority might specify that a fishery must achieve MSC certification, either as a general threshold for the domestic harvest sector or as condition for the entry of products into its market (Wessels et al. 2001).

Rights-based measures are a form of incentive towards win-win outcomes. When fishers are vested with secure harvesting rights, they can enjoy a secure and more direct flow of benefits from their fishing activities (ISSF 2011). At the individual level, secure rights can encourage fishers to fish at lower costs, increase the value of landings through selective fishing or catch handling, or change to a higher valued product (e.g., from frozen to fresh forms). In order to prevent high grading and discards, other controls may be required. Within rights-based management schemes, side payments become very important to balance the benefits against the costs (Libecap 1989). Side payments then are the Coasian bargain between winners and losers to keep the losers, so they continue to participate in the coalition and work towards sustainability. Side payments or benefit redistribution through Coasian bargaining can be essential to other types of interventions achieving triple bottom line outcomes. 


\section{Principle 6: Consider and Harness the Responsiveness of Stakeholders (Bottom-Up Matters)}

This principle seeks to address the complexity and heterogeneity of ABNJ fisheries by working from the bottom up across all sectors. Fisheries regulation is targeted at fishers and other actors within the catch sector and seafood supply chain (Grafton et al. 2010). This means regulators must take account of and respond to the cultures and understandings that operate within the sector (Baldwin and Black 2001). For example, fishers are often attached to historical practices or favor localized control. They may resent bureaucratic or technical management processes, or question scientific expertise. Regulation that accounts for and adapts to this is described as "sensitive regulation." The attitude of regulatees is a key variable in determining whether intended behavioral changes will flow from specific regulatory interventions.

Returning the discussion to the overarching smart mixes of interventions framework, these mixes have to work across different jurisdictions in transboundary fisheries, so understanding the institutional and social context that enables or constrains engagement by fishers in both public and private forms of regulation is vitally necessary for implementation (Barnes 2019). If these constraints are understood, we can better design and implement a combination of interventions and instruments that will be more clearly targeted and effective for changing fishing behavior.

At the international level, this means being sensitive to the motivations and capacity of States involved in the tuna fishery, as their actions may be conditioned by particular cultures and values.
While this publication does not aim to explore this point in detail, below are a few common cases pertaining to $\mathrm{ABN}$ f fisheries management:

- Fairness of allocation of fishing opportunities may be of paramount importance for small island developing states (SIDS), while historical practices or status quo may be more important for distant water fishing nations (Parris and Lee 2010). This situation has resulted in gridlock during management deliberations at certain RFMOs and/or the development of subregional agreements such as the PNA.

- The motivations of State representatives may differ from its industry. For example, reduction of overcapacity may be very desirable to industry; however, States where fisheries act as the employer of last resort may not be motivated to support capacity reduction measures during RFMO deliberations. In the exploration of the use of RBM, many States will add provisions to restrict rights trading that will retain sovereign rights that prevent the harvest sector from maximum rents (Gentner, 2018).

- Food security for some nations may have a higher priority than reforming fisheries management, even though the two are inextricably linked in the long run.

- Enabling conditions such as the state of socio-economic development, political systems, and cultures are variable across 


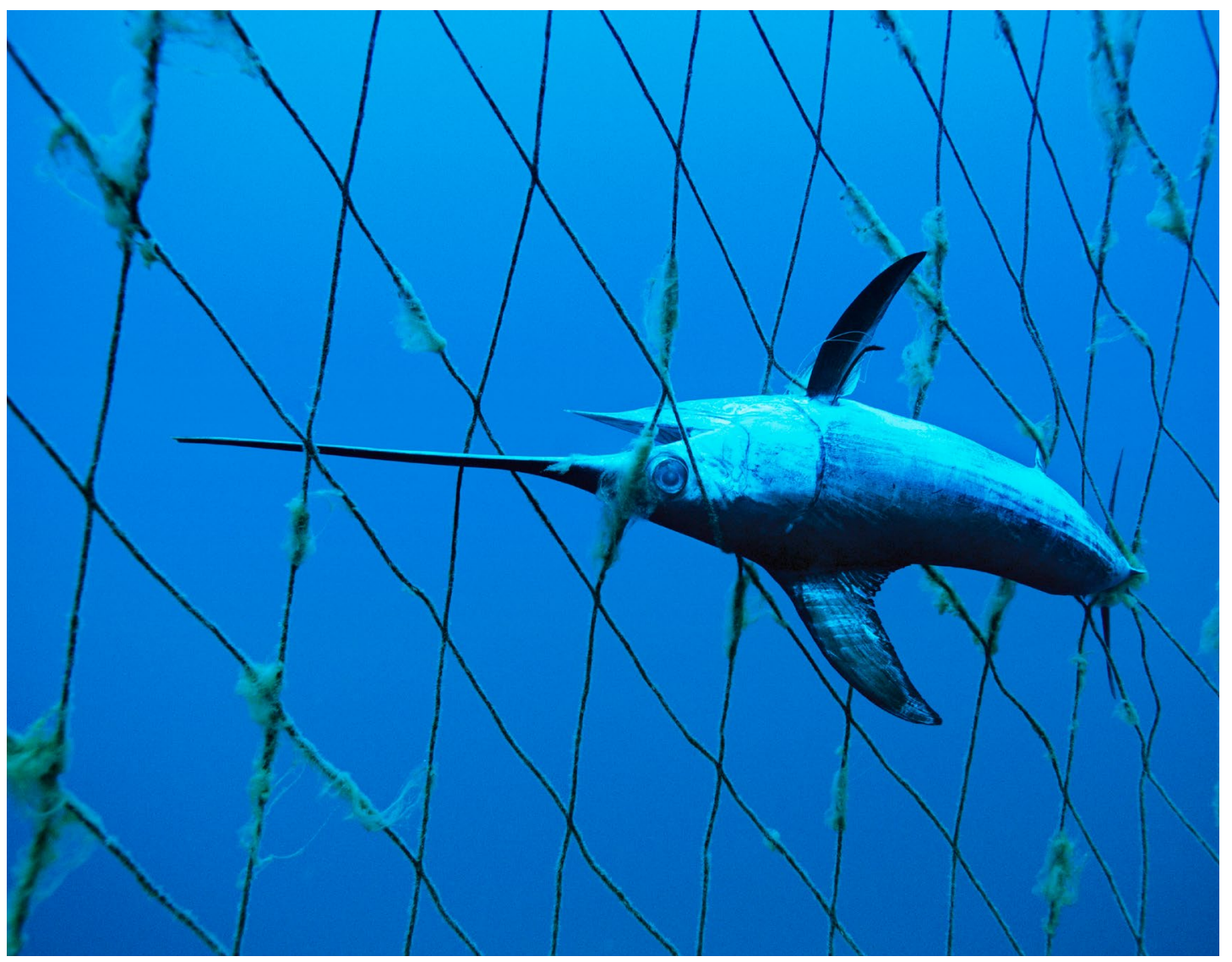

different regions, States, and localities. As a result, one set of measures may not work well for all contexts. Case Study 2 (Appendix) gives an example of recognizing local tenure arrangements and incorporating those arrangements in suggested interventions. In the Dominican Republic, there is severe crowding and conflict between recreational anglers and commercial fishers around the use of FADs that are placed mainly by commercial fishermen. Currently, on a seasonal basis some commercial fishers lease informal user rights around fish aggregating device (FAD) installations to recreational fishers. Building on this current practice to reduce conflict and billfish mortality, territorial use rights are being considered for FAD access. While this intervention may work in the Dominican Republic, it is unclear whether enabling conditions exist elsewhere for adoption.

- There may also be conflicts of interest among different sectors of an industry that influence the actions of States. The processing heavy industries - such as tuna canning - may be more concerned with reductions in the flow of product to their plants to avoid "idling capacity." On the other hand, the harvest sector may be more concerned about overall industry profitability, and are more likely to support measures that rationalize a fishery. Of course, there are several highly integrated sectors whose motives would vary between these two extremes. 
At the national or local level, more attention should be placed on private actors: individual fishers, commercial and industry groups, NGOs, and consumers. The following are typical motivating factors for actors in the fishing industry:

- Market factors: pursuit of profits, consolidation of market position, and brand reputation

- Reputation: congruence with industry norms, standing among peers, and influence

- Personal factors: familiarity with regulatory regimes and approaches, morality or ethical standards, balance of community/self interests, skills training, and enterprise

- Specific cultural norms and practices within the fishing community

Regulators and NGOs working to catalyze change need to understand how regulatees (from the global to local level) may respond to interventions in different ways: acquiescence, compromise, manipulation (game-playing), avoidance, or defiance. In addition, stakeholders may be responsive to different incentives. For example, penalties may elicit the intended behavior in some stakeholder groups, while other groups may be more responsive to rewards (Honneland 2001).
At the harvest stage, there are particular challenges with detection of conduct and compliance with rules. The marine spaces to be covered are extensive and distant from shore. Inspections at sea are expensive. Vessels are mobile and may operate across different jurisdictions. There are multiple and diffuse fishing concerns. There are multiple landing points for catch; hence, there may be many ways to avoid detection. Most detection and compliance strategies depend upon a high degree of self-reporting and self-compliance. To some extent, compliance with rules will depend upon the attitude and culture of regulatees. For example, regulations that expect unnatural conduct (discarding fish, using less efficient gear) may undermine self-regulation and give way to subversive conduct (landing catch under the radar). 


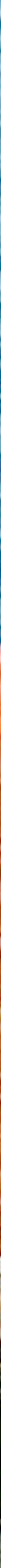




\section{Principle 7: Consider Top-Down Relationships, Opportunities, and Constraints}

The goal here is to focus on the umbrella that overarches any intervention design strategy. Thus, there needs to be compatibility of the complete intervention plan with existing regulations, legal constraints, unintended consequences, and spillover effects (Taylor et al. 2013). Success of a bottom-up strategy at the ABNJ level requires scaling those interventions up across States and ultimately RFMOs. It is important to be aware of the differences in jurisdictions and levels of governance, and wherever possible accommodate important elements in the application of incentive-based tools. This involves understanding how incentives for compliance are distributed across different levels of governance, and recognizing that different instruments may have impacts at different levels. Critically important governance structures that need to be accounted for when designing and implementing interventions are highlighted below.

\section{Legal and Institutional Constraints}

The law of the sea is strongly institutionalized (Barnes 2018). Each agreement builds on and supports previous agreements. Treaties are only binding on State parties. They do not as a general rule create rights and duties for non-parties. This means the effectiveness of rules for the high seas depends upon securing maximum agreement among States. The law is strongly integrated, with many rights and duties linked to others. States are inclined to follow established practices and rules. The process for change in treaties is slow and difficult, which calls for incentives and "soft law" approaches to address governance gaps.
The high seas are governed by the fundamental principle of freedom of the high seas, which includes fishing. However, freedom to fish is conditional, subject to general obligations to cooperate, conserve, and manage resources. On the high seas, fishing is subject to the exclusive control of the flag States. These factors place limits on the strength of RBM measures adopted for high seas fisheries. RFMOs and States cannot guarantee full exclusivity of tenure rights, so first best RBM solutions are unlikely to be adopted. There is the risk that Third States that do not recognize such rights can undermine them by fishing stocks to which the rights pertain.

At the international level, fisheries conservation and management must be done with due regard to the rights and interests of other States, ${ }^{2}$ reaffirming the connectivity of issues and regulatory logic of United Nations Convention on Law of the Sea (UNCLOS).

The wide management discretion possessed by RFMOs means there is no legal impediment to the adoption of incentive-based tools (Serdy 2010). The only restriction is that the choice of regulatory tool or approach should deliver conservation outcomes. Most RFMOs allocate rights to States, rather than individuals.

Case Study 7 (Appendix) looks at the allocation issue relative to the legal and institutional constraints facing allocation decisions. International fisheries law has poorly defined approaches to allocation. Because allocations are based on past catches, it can be difficult to 
re-distribute harvest rights to meet social, economic, or conservation goals of new entrants. However, this can be resolved through set-asides and limited-duration tenure systems. RBM with rights trading can improve rents in a fishery and at the same time help meet conservation goals through distributing rights most efficiently. However, trade can be viewed as a threat to sovereign rights allocated by RFMOs. If allocations are viewed as unfair, there will be incentives to ignore restrictions or subvert rules (Nielsen 2003). Some RFMOs are attempting to address this concern by developing allocation criteria. Participatory rights and allocations are a key lever to incentivize non-Member States to adhere to RFMO rules. But using allocations in this way may require reducing current allocations across Members. Unless allocation criteria change, the further use of incentive-based tools will need to be directed by individual States.

\section{Regulatory Logics}

Being aware of and balancing these logics is key to selecting and implementing the mix of instruments to be used. If instruments with different logics are used, they can come into tension with each other. For example, RBM entails a higher degree of market input. Holders of RBM may then resist command-and-control measures because they impact upon the value and operation of market forces (Barnes 2009). At the international level, the dominant logic is that law is the product of State consent or consensus (Guzman 2002). As such, there is strong resistance to regulatory frameworks that impose rights and duties automatically, or which empower intergovernmental organizations to make binding decisions. Thus, RFMOs operate through consensus-based decision-making combined with opt-out procedures (McDorman 2005). This means decision-making is invariably based upon compromise, and individual States can hold out or free ride on the acts of other States, e.g., benefiting from restrictions in fishing effort (Kaitala and Munro 1997). Other less dominant logics include sensitivity to the needs of developing States with a real interest in the fishery (e.g., Article 25 of the United Nations Fish Stocks Agreement (UNFSA).

RFMOs possess sufficient authority as is required for them to carry out their functions (Serdy 2010). This will vary according to the function of the RFMO, but could be potentially broad in so far as is necessary to conserve and manage fish stocks. It is unclear whether the authority of RFMOs can extend to obtaining and holding investment agreements with financial institutions. 


\section{Principle 8: Assess and Adapt the Smart Mix in Light of Its Effectiveness}

A successful system of smart mix interventions must be designed with the capacity to adapt to changing circumstances, assess performance against goals, and allow "learning" by regulators. It is important that the effectiveness of this system be holistically assessed at appropriate intervals and modified accordingly (Baldwin and Black 2008).

Smart mix approaches should be adaptable to changed circumstances. This may be internal, such as adapting to changed policy, or external, such as responding to new technology or environmental conditions. Some aspects of the high seas fisheries governance regime are able to adapt more easily than others (Barnes 2018). UNCLOS contains mechanisms for amendment or modification, but these impose procedural barriers so stringent that amendment or modification is all but impossible (Boyle 2006). The same is true of the UNFSA. However, UNCLOS and the UNFSA are sufficiently broad to sustain a wide range of regulatory options, including incentive-based tools.

Case Study 8 (Appendix) demonstrates this principle with respect to the international legal framework. The United Nations Review Conference for UNFSA found that improvements were still required in the management of marine capture fisheries (UNGA 2016). ${ }^{3}$ Its report called upon States to take measures, consistent with international law, to ensure that only fish caught in accordance with applicable conservation and management measures reach their markets, and to take steps consistent with international and domestic law to require those involved in fish trade to cooperate fully to this end. It presented a number of recommendations, including the adoption of market-related measures. These recommendations led to United Nations Food and Agriculture Organization (FAO) voluntary guidelines on catch documentation schemes and support for MCS-related initiatives.

Change to the legal regime is best advanced at regional and local levels. This can be done through the reform of RFMO constituent instruments. Another option is to establish sub-regional arrangements, which has occurred in the Western Central Pacific with the establishment of the PNA sub-regional body.

Case Study 4, in the Appendix, is another example of adaptation by highlighting several important details of the PNA vessel day scheme (VDS). This rights-based program is one of the longest running RBM programs in ABNJ fisheries. While it has been widely viewed as a success, achieving many of its goals, there have been several criticisms. As a result, the PNA commissioned a full and independent assessment of the VDS to improve the program (PNA 2015). The review contained suggestions across a wide range of issues raised by prior critiques of the VDS. Several of these suggestions were adopted to meet the program goals of improving the collection of fishery rents and the conservation of the stocks under management. 


\section{Principle 9: Assess Opportunities for Better Interventions}

Principle 9 requires evaluation of the potential impacts of interventions that are not in the current smart mix design, with a view to adoption based on expected performance. Such assessments may be required by law, or are a common feature of institutional practice. A review of regulatory strategies and other interventions should be planned to ensure that systems as currently designed have not outgrown their effectiveness (Baldwin, Cave and Lodge 2012). A good example of a smart mix system that has met its limits is the current suite of measures to manage the mortality of tropical tunas in the Eastern Pacific purse seine sector. The InterAmerican Tropical Tuna Commission (IATTC) manages this purse seine sector through a combination of closed seasons, area closures, and vessel hold capacity limits. When these measures were first enacted, they worked reasonably well to manage fishing mortality. However, as seasonal closures continue to increase, it is clear that these measures have met their effectiveness limit and new incentive-based measures are needed to secure the sustainability of the stocks and the industry dependent on these fisheries (Maharaj, 2019).

Regulatory assessments may involve two elements: some form of cost/benefit analysis of a new regulatory tool (regulatory impact assessment); and the assessment of the impact of a particular decision, e.g., environmental impact assessment or social impact assessment (Barnes 2019).
Outside of the regulatory process, the growth of investment opportunities will drive other forms of impact assessment because investors will require detailed appraisals of either social outcomes from investment, or financial returns. This will entail assessment of contextual and regulatory changes on fisheries, i.e., investment risks and returns. It may also drive the potential for regulatory reform as a way of securing investment returns.

Impact assessment is not limited to regulatory processes or decision-making on specific projects by public bodies. It also forms an integral part of business planning. This can be integrated into broader policy agendas when new development opportunities are being considered, as demonstrated through the regional business cases developed as part of the OPP program (See Case Studies 2 and 9 in the Appendix). Both cases show that by using a business case framework, stakeholders are engaged in the estimation of the impacts of the interventions they helped to design, increasing buy-in to the ultimate goal of management reform. The Common Oceans web page has a repository of all supporting documents generated under the OPP projects. ${ }^{4}$ This resource contains the outputs of all assessments used to design the business cases that include the potential impacts of interventions being considered.

Case Study 9 (Appendix) is another good example of how a holistic process of stakeholder engagement early in a business case development phase both allows for a quality 
impact analysis using better data and also increases stakeholder buy-in for the business case. WWF has engaged IATTC members and stakeholders to assess alternatives to reduce bigeye and yellowfin tuna recruitment overfishing and reduce overall excess capacity in the fleet for a number of years. WWF, IATTC, and other organizations such as ISSF have sponsored a number of studies and workshops to develop the impacts of potential interventions and seek stakeholder buy-in. Through the OPP projects, WWF began with the FPIs, as in Case Study 2, engaging stakeholders early in the business case design process. Through this process WWF commissioned two studies estimating the impacts of an individual vessel quota (IVQ) for bigeye and yellowfin tuna in the purse seine fleet, and the impacts of a vessel buyback and other capacity reduction alternatives. The outputs of both of those studies are currently being used to craft two formal business cases to address excess capacity and bigeye and yellowfin tuna recruitment overfishing. Outputs of these analyses are also being used by the IATTC in the development of its capacity management plan.

Assessments should seek to present data and scenarios that informed the development of incentive-based tools. The assessment should be supplemented by data from expert studies, as in the OPP business case development described in the preceding paragraph. Beyond assessment of current or proposed interventions, it is important to look at follow-on impacts and the impacts of exogenous shocks to the system, such as the impacts of changing market conditions and the impacts of new technology.

\section{Market Changes}

Because tuna markets are global, fluctuations in supply and demand in regional fisheries cannot be assessed in isolation. For example, increased demand for skipjack tuna is likely to be met by the Western Central Pacific Ocean (WCPO) since Atlantic stocks are at current limits, and the WCPO seems to have the greatest capacity to expand (World Bank 2016). Global population and demand for protein (including seafood) is rising, especially in China, India, and developing countries. While it is expected that much of this increased demand will be met by aquaculture, increasing pressures from countries such as China for larger allocations of fishing entitlements of $\mathrm{ABNJ}$ fisheries are important realities for multilateral negotiations. The cost of fishing must factor in increased fuel costs, which comprise the largest cost for both purse seine and long line fishing (estimated at 25 percent and 44 percent respectively) (Conservation International 2015). Fuel costs are expected to increase 100 percent in real terms by 2040 .

\section{Harvesting Technology}

Harvesting technology is expected to improve and become more efficient, offsetting some costs associated with fuel. Advances in fisheries monitoring and surveillance (e.g., VMS, satellite monitoring, surveillance drones, and electronic fishery information systems) should reduce enforcement costs and facilitate improved management. Improvements in vessel capacity and storage could enhance product quality (World Bank 2016). Increased efficiency, larger vessels, and higher dependence on fishing technology will make it more difficult for new fishers to enter the market and compete with existing fleets. Access to technology will require investment. This will come from larger, more profitable actors and possibly from other actors in the supply chain (canneries, retailers), or from external investors. There is scope to combine capital flows into the industry with investment-based incentives. The need for investment will drive a move towards greater legal security over fishing rights. 


\section{Conclusion}

Overall, design of successful smart intervention mixes for ABNJ fisheries is not a rapid process, and the process itself should be iterative and adaptive. The theory of change presented here is not necessarily different than a theory of change that could be applied to any fisheries management reform. The difference for the ABNJ case is the heterogeneity and complexity of all the sectors involved, the lack of well-defined legal instruments governing the high seas, and the scale and scope of the multilateral issue. However, by segmenting the problem into manageable parts, sequencing the "right" mix of interventions that include incentives and scaling up over time, the larger ABNJ problem can be tackled.
There is no single intervention that will solve the problem of ABNJ fisheries. They are a complex problem that can only be addressed with a smart mix of interventions. The nine principles discussed in this report can guide the application of smart mixes into the management of ABNJ fisheries. These design principles are a positive way forward in complex, adaptive systems where no single entity is in control and there is a critical need for change. 


\section{References}

Anderson, J.L., C.M. Anderson, J. Chu, J. Meredith, et al. "The Fishery Performance Indicators:

A Management Tool for Triple Bottom Line Outcomes." PLOS ONE 10(5): e0122809. doi:10.1371/journal.pone.0122809 (2015). At http://journals.plos.org/plosone/ article?id=10.1371/journal.pone.0122809.

- "The Fishery Performance Indicators Manual," Version 1.2 (2014). At https://doi.org/10.1371/ journal.pone.0122809.s004.

Anderson, J.L., T. Garlock, C. Crandall. "Sport Fishery Performance Indicators Manual: A New Instrument in the FPI Toolbox," Version 1.0 (2017).

Ardron, J.A. et al. "The sustainable use and conservation of biodiversity in ABNJ: What can be achieved by using existing agreement?" Marine Policy 49:98-108 (2014).

Arnason, R. "Fisheries management and operations research." European Journal of Operational Research 193 (2009). 741-751.

Arnason A., R. Hannesson, W.E. Schrank. "Costs of fisheries management: the cases of Iceland, Norway and Newfoundland." Marine Policy 24: 233-243 (2000).

Bailey, M. et al. "Moving beyond catch in allocation approaches for internationally shared fish stocks." Marine Policy 40: 124-136 (2013).

- "Closing the Incentive Gap: The Role of Public and Private Actors in Governing Indonesia's Tuna Fisheries." Journal of Environmental Policy and Planning 18:141-160 (2016).

Baldwin, R., M. Cave, M. Lodge. Understanding Regulation. Theory, Strategy and Practice. Oxford: Oxford University Press, 2012.

Baldwin, R. and J. Black. "Really Responsive Regulation." Modern Law Review 71: 59-94 (2008).
Barnes, R. Property Rights and Natural Resources. Oxford: Hart, 2009.

. "Flag States." D.R. Rothwell, A.G. Oude Elferink, K.N. Scott, T. Stephens (eds.), The Oxford Handbook on the Law of the Sea. Oxford: Oxford University Press, 2015. 304-324.

"The Proposed LOSC Implementation Agreement on Areas Beyond National Jurisdiction and Its Impact on International Fisheries Law." International Journal of Marine and Coastal Law 31:583-619 (2016).

. "Assessing the application of innovative incentive-based tools to reform highly migratory fisheries from the regional to the global scale." WWF/G/oTT Report, 2018.

. "The Pursuit of Good Regulatory Design Principles in International Fisheries Law: What Possibility of Smarter International Regulation?" J. van Erp, M. Faure, A. Nollkaemper and N. Philipsen (eds.), Smart Mixes of Environmental Governance. Cambridge University Press, in press, 2019.

Bennear, L.S. and R.N. Stavins. "Second-best theory and the use of multiple policy instruments." Environmental and Resource Economics 37:111-129 (2007).

Bladon, A. et al. "Payments for ecosystem services in developing world fisheries." Fish and Fisheries 17: 839-859 (2016).

Blanchard, C. "Fragmentation in high seas fisheries: Preliminary reflections on a global oceans governance approach." Marine Policy 84:327-332 (2017).

Boström, M. et al. "Sustainable and responsible supply chain governance: challenges and opportunities." Journal of Cleaner Production 107: 1-7 (2015).

Boyle, A. "Further Development of the 1982 Convention on the Law of the Sea." D. Freestone, R. Barnes, D. Ong (eds.), Law of the Sea. Progress and Prospects. Oxford: Oxford University Press, 2006. 
Bush, S. et al. 'The 'devils triangle' of MSC certification: Balancing credibility, accessibility and continuous improvement." Marine Policy 37: 288-293 (2013).

Bush S.R., and P. Oosterveer. "Vertically Differentiating Environmental Standards: The Case of the Marine Stewardship Council." Sustainability 7: 1861-1863 (2015).

Bush S. et al. "Private provision of public information in tuna fisheries." Marine Policy 77: 130-135 (2017).

Cochrane, K., C. De Young, D. Soto, T. Bahri (eds). "Climate change implications for fisheries and aquaculture: overview of current scientific knowledge." FAO Fisheries and Aquaculture Technical Paper No. 530 (2009). Rome: FAO.

Cox, A. "Quota Allocation in International Fisheries." OECD Food, Agriculture and Fisheries Papers, No. 22 (2009). Paris: OECD Publishing.

Cunningham, S. et al. "Wealth-based Fisheries Management: Using Fisheries Wealth to Orchestrate Sound Fisheries Policy in Practice." Marine Resource Economics 24: 271-28 (2009).

Environmental Defense Fund and Nicholas Institute for Environmental Policy Solutions at Duke University (EDF). "Financing fisheries reform: Blended capital approaches in support of sustainable wild-capture fisheries" (2018). At https://www.edf.org/sites/ default/files/documents/financing-fisheriesreform.pdf.

Encourage Capital. Investing for Sustainable Global Fisheries (2016). At http://investinvibrantoceans. org/wp-content/uploads/documents/FULLREPORT_FINAL_1-11-16.pdf.

FAO. Indian Ocean Tuna Management Workshops on implementation of the precautionary approach and rights-based management. ABNJ-Tuna-2014-TR1-MSE-WS (2014). At http://www.fao.org/3/aat148e.pdf.

-. "Technical and Socio-Economic Characteristics Of Small-Scale Coastal Fishing Communities, And Opportunities for Poverty Alleviation and Empowerment." Fisheries and Aquaculture Circular 1111 (2016). Rome: FAO.

. Voluntary Guidelines for Catch Documentation Schemes, Rome: FAO, 2017.
___. "Report of the Fifth Global Fisheries Enforcement Training Workshop, Auckland, New Zealand, 7-11 March 2016." FAO Fisheries and Aquaculture Report No 2103 (2017). Rome: FAO.

Gentner, B. "Assessing the application of innovative incentive based tools to reform highly migratory fisheries at the project development and regional scales." Report prepared for the World Wildlife Fund, Washington, DC, USA, 2018.

Gentner, B., R. Bealey, K. Flett, R. van Anrooy, P. Obregon. "Fishery Performance Indicators, Cash Flow Models and Fishery Project Development: A Case Study of the Pelagic Fisheries in Grenada and the Dominican Republic." FAO Fisheries and Aquaculture Circular. Rome: FAO, 2018. In press.

Gilman, E. and E. Kingma. "Standard for assessing transparency in information on compliance with obligations of regional fisheries management organizations: Validation through assessment of the Western and Central Pacific Fisheries Commission." Ocean and Coastal Management 84: 31-39 (2013).

Grafton R.Q. et al. "Incentive-based approaches to sustainable fisheries." Canadian Journal of Fisheries and Aquatic Sciences 63:699-710 (2006).

Grafton, R.Q. et al. (eds.) Handbook of Marine Fisheries Conservation and Management. Oxford: Oxford University Press, 2010.

Gunningham, N. "Environment Law, Regulation and Governance: Shifting Architectures." Journal of Environmental Law 21: 179-212 (2009).

Gunningham, N. and Grabosky, P. (eds.). Smart Regulation: Designing Environmental Policy. Oxford: Clarendon Press, 1998, chap. 2.

Gunningham, N. and J. Rees. "Industry Self-Regulation: An Institutional Perspective." Law \& Policy 19: 363414 (1997).

Gunningham N. and D. Sinclair. "Smart regulation." P. Drahos (ed.) Regulatory Theory, Foundations and Applications. ANU Press, 2017. 133-148.

. "Regulatory Pluralism: Designing Policy Mixes for Environmental Protection." Law \& Policy 21: 49-76 (1999). 
Guzman, A.T. "A Compliance-Based theory of International Law." California Law Review 90: 1823 (2002).

Hahn, R.W. "Policy Watch: Government Analysis of the Benefits and Costs of Regulation." Journal of Economic Perspectives, 12(4): 201-210 (1998).

Hahn R.W. and R.N. Stavins. "Incentive-Based Environmental Regulation: A New Era from an Old Idea." Ecology Law Quarterly 18:1 (1991).

Hanich, Q.A. et al. Closing the gaps: building capacity in Pacific fisheries governance and institutions. Pacific Islands Forum Fisheries Agency, Honiara, 2008.

Hatanaka, M. and L. Busch. "Third-Party Certification in the Global Agrifood System: An Objective or Socially Mediated Governance Mechanism?" Sociologia Ruralis 48: 73-91 (2008).

Hatcher, A.C. "Producers' organizations and devolved fisheries management in the United Kingdom: Collective and individual quota systems." Marine Policy 21: 519-533 (1997).

Hatcher, S. et al. "Normative and social influences affecting compliance with fisheries regulations." Land Economics 76: 448-461 (2000).

Havice, E. "Rights-based Management in the Western and Central Pacific Ocean Tuna Fishery: Economic and Environmental Change under the Vessels Day Scheme." Marine Policy, Vol. 42, 259-267 (2013).

Hilborn, R. and J. Sibert. "Adaptive management of developing fisheries." Marine Policy 12: 112-121 (1998).

Honneland, G. "Recent Global Agreements on High Seas Fisheries: Potential Effects on Fisherman Compliance." OS Stokke (ed.) Governing High Seas Fisheries: The interplay of Global and Regional Regimes. Oxford: Oxford University Press, 2001.

Howlett, M. and J. Rayner. "Designing Principles for Policy Mixes: Cohesion and Coherence in 'New Governance Arrangements."' Policy and Society 26: $1-18$ (2007).

ISSF. Cordoba Conference on the Allocation of Property Rights in Global Tuna Fisheries, 2011.
Jacquet, J.L. and D. Pauly. "The rise of seafood awareness campaigns in an era of collapsing fisheries." Marine Policy 31:303-313 (2007).

Jentoft, S. "Legitimacy and disappointment in fisheries management." Marine Policy 24: 141-148 (2000).

Kaitala, V.T. and G. Munro. "The conservation and management of high seas fishery resources under the new Law of the Sea." Natural Resource Modeling 10: 87-108 (1997).

Khan, A.M.A. et al. "Impact of a fishing moratorium on a tuna pole-and-line fishery in eastern Indonesia." Marine Policy 94:143-149 (2018).

Lewis, S.G. and M. Boyle. “The expanding role of traceability in seafood: tools and key initiatives." Journal of Food Science 82(S1): pp. A13-A21 (2017).

Libecap, Gary D. "Distributional Issues in Contracting for Property Rights." Journal of Institutional and Theoretical Economics (IITE) / Zeitschrift Für Die Gesamte Staatswissenschaft 145, no. 1: 6-24 (1989).

. "Addressing Global Environmental Externalities: Transaction Costs Considerations." Journal of Economic Literature 52: 424-79 (2014).

Lodge, M.W. et al. Recommended Best Practices for Regional Fisheries Management Organizations Report of an Independent Panel to Develop a Model for Improved Governance by Regional Fisheries Management Organizations. Chatham House, 2007.

Maharaj, V. "Complications of designing tenure rights programs for highly migratory fisheries: Eastern Pacific Tropical Tuna Fisheries." Proceedings of Tenure and UserRights 2018: Achieving Sustainable Development Goals by 2020. Yeosu, South Korea: UN Food and Agriculture Organization. In press, 2019.

Manta Consulting. Financing Fisheries Change, 2011. At http://www.conservation.org/publications/ Documents/Manta-Consulting-FinancingFisheries-Change.pdf.

McCauley, D.J. et al. "Wealthy countries dominate industrial fishing." Science Advances 01 Aug 2018: Vol. 4, no. 8. 
McClanahan, T.R. et al. "Healing small-scale fisheries by facilitating complex socio-ecological systems." Reviews in Fish Biology and Fisheries 19:33 (2009).

McDorman, T.L. "Implementing existing tools: turning words into actions-decision making processes of regional fisheries management organizations (RFMO)." International Journal of Marine and Coastal Law 20: 423-457 (2005)

Muradian R., et al. "Payments for ecosystem services and the fatal attraction of win-win solutions." Conservation Letters 6(4): 274-279 (2013).

Nielsen, J.R. "An analytical framework for studying: compliance and legitimacy costs in fisheries management." Marine Policy 27: 425-432 (2003).

Northern Economics. Alternatives to address capacity in the Eastern Pacific Purse Seine Fishery. Report prepared for the Word Wildlife Fund Inc, Washington, DC, 2018

Parkes, G., J.A. Young, S.F. Walmsley, R. Abel, J. Harman, P. Horvat, A. Lem, A. MacFarlane, M. Mens, C. Nolan. "Behind the signs - a global review of fish sustainability information schemes." Reviews in Fisheries Science, 18(4), pp. 344-356 (2010).

Parkes, G. et al. "Review of Fish Sustainability Information Schemes - Final Report" (2009). At http://cels.uri. edu/urissi/docs/FSIG_Report.pdf.

Parris H. and A. Lee. "Allocation Models in the Western and Central Pacific Fisheries Commission and Implications for Pacific Island States." Q. Hanich and M. Tsamenyi (eds.). Legal and Policy Regimes in the Western and Central Pacific Fisheries, 2009.

Pascoe, S. et al. "Use of Incentive-Based Management Systems to Limit Bycatch and Discarding." International Review of Environmental and Resource Economics 4(2): 1-39 (2010).

Pomeroy, R.S. "Community-based and co-management institutions for sustainable coastal fisheries management in Southeast Asia." Oceans \& Coastal Management 27: 143-162 (1995).

Purcell, S.W. et al. "Distribution of economic returns in small scale fisheries for international markets: A value chain analysis." Marine Policy 86: 9-16 (2017).
Rayfuse, R. "Regional Fisheries Management Organizations." D. Rothwell et al. (eds.), The Oxford Handbook of the Law of the Sea. Oxford: Oxford University Press, 2015, p. 439

Roheim, C. A., S.R. Bush, F. Asche, J.N. Sanchirico, H. Uchida. "Evolution and future of the sustainable seafood market." Nature Sustainability, 1(8), 392 (2018).

Roheim, C. "Seafood Supply Chain Management: Methods to Prevent Illegally-Caught Product Entry into the Marketplace." Paper prepared for International Union for Conservation of Nature, Gland, Switzerland. 2008.

Sampson, G.S., J.N. Sanchirico, C.A. Roheim, S.R. Bush, J.E. Taylor, E.H. Allison, J.L. Anderson, N.C. Ban, R. Fujita, S. Jupiter, J.R. Wilson. "Secure sustainable seafood from developing countries." Science 348(6234):504-506 (2015).

Serdy, A. "International fisheries law and the transferability of quota: principles and precedents." R. Allen, J. Joseph, D. Squires (eds.), The conservation and management of transnational tuna fisheries. Ames: Wiley-Blackwell, 2010, p. 199-126.

The New Entrants Problem in International Fisheries Law. Cambridge: Cambridge University Press, 2016.

Smith, M. "The New Fisheries Economics: Incentives Across Many Margins." Annual Review of Resource Economics 4: 379-402 (2012).

Sullivan, J. "Comparison of Wild-Capture Fisheries Certification Schemes - Update." Report prepared for the World Wildlife Fund. Gland, Switzerland, 2012. Last accessed 11/27/18 at https://c402277. ssl.cf1.rackcdn.com/publications/488/files/ original/wwf_report_comparison_wild_capture fisheries_schemes_2_pdf?1354205790.

Sutinen, J. et al. "Measuring and explaining noncompliance in federally managed fisheries." Ocean Development and International Law 21: 335372 (1990).

Taylor, C.M., Sophie Rocks et al. "Better by design: Rethinking interventions for better environmental regulation." Science of The Total Environment 447: 488-499 (2013). 
van Gossum, P., B. Arts and K. Verheyen. "From 'Smart Regulation' to 'Regulatory Arrangements."' Policy and Science 43(3): 245-261 (2010).

United Nations General Assembly. "Report of the resumed Review Conference on the Agreement for the Implementation of the Provisions of the United Nations Convention on the Law of the Sea of 10 December 1982 relating to the Conservation and Management of Straddling Fish Stocks and Highly Migratory Fish Stocks." UN Doc. A/ CONF.210/2016/5 (2016).
Wessells, C.R., K. Cochrane, C. Deere, P. Wallis, R. Willmann. "Product certification and ecolabelling for fisheries sustainability." FAO Fisheries Technical Paper No. 422, 2001. Rome: FAO.

Young, M. "Fragmentation or Interaction: the WTO, Fisheries Subsidies and International Law." World Trade Review 8:477 (2009). 


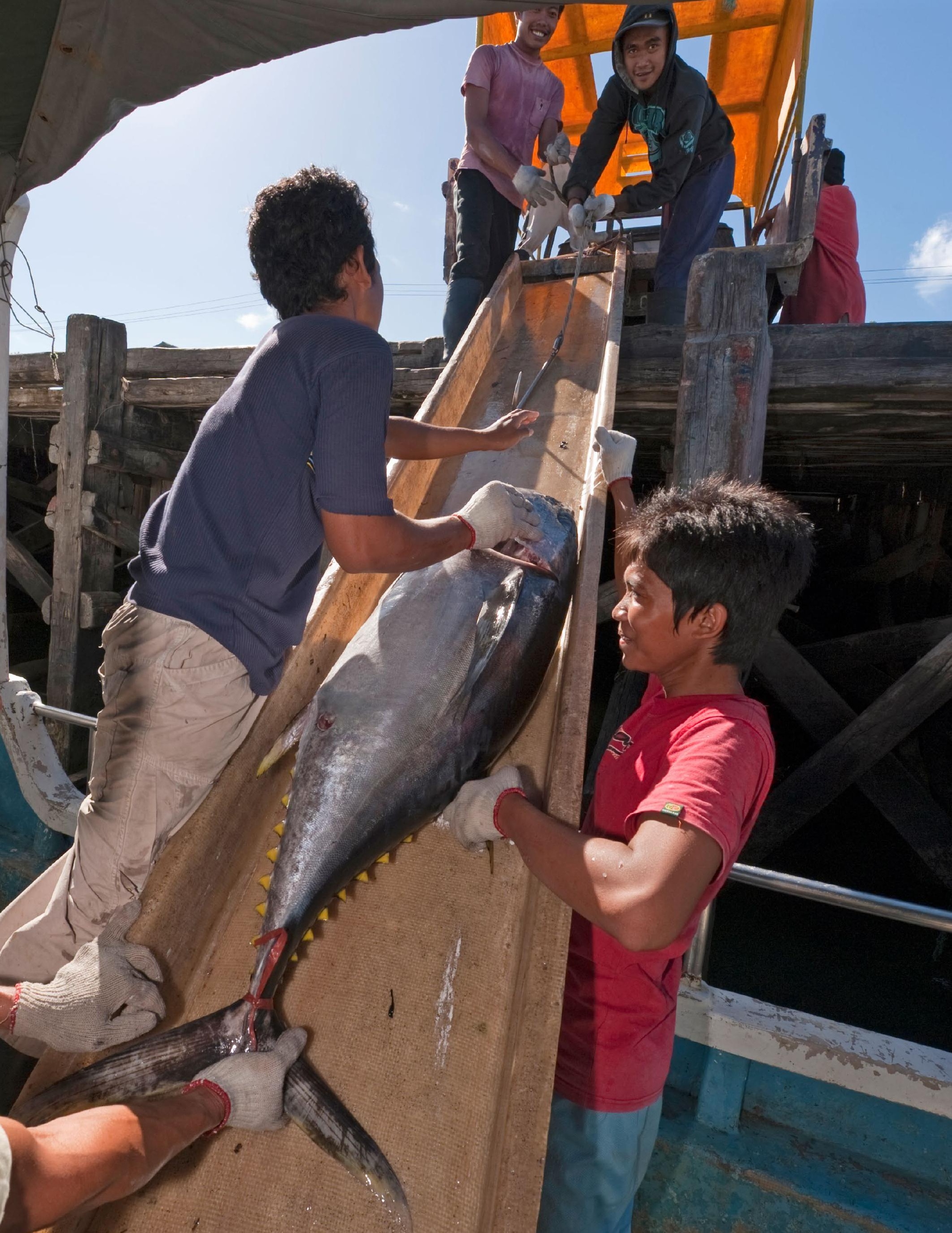




\section{Appendix: Case Studies}

\section{Case Study 1: Investment and RBM}

Sequencing is important when building a smart mix of interventions, particularly when those interventions utilize private investment. Investment requires a strong and secure regulatory environment (Barnes, 2018). The introduction of RBM can provide some level of security, but additional measures may be required to build the proper institutional foundation. Investment can be a tool to drive the creation of RBM and facilitate the creation of other institutions to enable RBM and enhance sustainability outcomes. For example, investments could create transferable catch rights programs by funding appropriate monitoring and other requirements for catch shares to function effectively. If there is excess capacity, or fishing capacity is not distributed fairly across participants in a fishery, then investment can be used to facilitate capacity transfers or removal. In many fisheries, capacity reduction has been done through state funding initiatives (e.g., European Maritime and Fisheries Fund). The removal or transfer of capacity could be driven by private investment, or combinations of public and private investment. However, this is likely to require some form of return on the initial investment. More specifically, investment requires some form of security in fisheries, typically in the form of secure tenure rights, catch limits, and robust monitoring and enforcement capacity. If these conditions do not exist, then investors will not be interested in providing financing. The lack of property or security for investment is the main reason capital input into fisheries has mainly taken the form of grants, and so few debt/equity or program-related investments (PRI) have gone into emerging market fisheries projects. This speaks directly to the need for instrument mixes that contain the correct, or compatible, instrument combinations to reach the goal of privately financed capacity reductions.

In 2014, an ISSF-led expert workshop on capacity transfer explored the conditions for a successful investment environment (ISSF 2014). While this was done in the context of evaluating capacity transfer options, the general investment conditions are relevant to any scenario in which investment in fisheries is being considered. The various conditions enabling investment included a conducive political and economic environment; a secure legal framework for investment; cultural/social ties and networks; economic conditions/production inputs; availability of fish; market accessibility, trade agreements, and partnership; entrepreneurship; willingness to invest and risk; availability of finance; and voluntary and market-based transfers/investments. 


\section{Case Study 2: Caribbean Projects Under the OPP}

The Western Central Atlantic region was selected as an area of focus under the OPP ABNJ project (Gentner 2018). Within that regional focus, Grenada and the Dominican Republic were selected as pilot countries. One of the goals of the OPP project in the Caribbean was to reduce billfish harvest in the commercial sector. The Caribbean project is structured in such a way that in a three to four-year period it can achieve the following results:

Result 1.1. Enhanced knowledge and understanding of the socio-economic and ecological value of billfish resources in the Western Central Atlantic, and a clear value proposition for reform of current billfish governance structures.

Result 1.3. Pilot trials established in at least two Caribbean states (countries or overseas territories) to test and validate innovative management and supporting arrangements. Lessons learned will inform regional approaches in developing and adopting the billfish management and conservation plan for the Western Central Atlantic.

Result 4.1. Business cases for pilot investment projects on sustainable management and conservation of billfish in up to two locations in the Caribbean.

Using a business case approach disciplines the process of assessing impacts of an intervention that is also beneficial to outside funders. It is a process that will identify the strengths and weaknesses of a particular fishery and how those conditions can be addressed through external financing. A business case will also identify the right mix of funding for the success of a particular project. Any intervention contains investment in public goods, such as stock assessments and data collection, and private goods, such as improved supply chains and better market access. Understanding the impacts of each type of investment is highlighted by the business case process. Gentner et al. (2018) detail the holistic process of rapid assessment to final business case development in the two Caribbean pilot countries of Grenada and the Dominican Republic.

Using fishery performance indicators (FPIs). An intervention strategy is fundamentally underpinned by research and information about the state of the resource, the actors, and institutions, including market and consumer expectations. Enhancing information can be regarded as a low level intervention and a precursor to stronger targeted interventions. Fishery researchers and management professionals have developed toolkits to rapidly assess the generation of ecological, economic, and community impacts from fisheries, and to identify the management structures, governance methods, and regulatory instruments that promote successful outcomes (improved ecological, economic, and community benefits). The Fishery Performance Indicators (FPIS), developed by Anderson et al. (2015), were designed to also capture how fishery resources are contributing to the wealth of communities that depend on them, and to document benchmark factors that support wealth generation. Both recreational and commercial sectors can be captured using this rapid assessment tool (Anderson et al. 2014; Anderson et al. 2017).

The FPIs include over 60 measures for assessing wealth accumulation in terms of multiple dimensions of stock, harvest industry performance, and post-harvest industry performance; and over 50 measures of enabling factors-including management and governance-to associate with variation 
in wealth outcomes. Each measure is scored-accurately, but with low precision-on a one-to-five scale using data where possible, but relying primarily on non-quantitative factors that can be scored by experts in any fishery or fishery sector. This feature makes it particularly well-suited to applications in data-poor countries or industry sectors.

When FPIs are used as the first stage of a larger more holistic fishery development project design, as used in the Caribbean OPP project, they can become the platform for data collection, financial modeling, and stakeholder engagement. Ultimately, the design of the entire intervention package being put forward for investment in Grenada and perhaps the Dominican Republic can draw extensively from the FPI results. Gentner et al. (2018) detail this entire process, from FPI to completed business case. They show that the whole can be greater than the sum of the parts when cost, conflict, and targeting are treated holistically using well-designed rapid assessment tools such as the FPIs.

Taking advantage of existing rights structures (Gentner 2018). The Dominican Republic commercial pelagic fishery uses a large number of inexpensive FADs scattered in an area of high recreational billfish effort in the most popular recreational billfish destination in the Caribbean. Early in the project, an area based rights or territorial use right (TURF) was proposed, with FADs being the property right. The right is a weak right, as excludability can only be enforced on the FAD itself. However, a TURFs assigned to FADs would reduce congestion and conflict between commercial fishermen and between commercial and recreational fishermen. It may be possible to improve stock conditions as well, if side payments or FAD improvements can be utilized to convince FAD fishermen to use circle hooks when using bait, and/or to release all billfish alive.

This approach is attractive for a number of reasons. First, congestion and conflict are very high in some regions, and that congestion and conflict is rent-reducing. Second, it is unlikely that a regionwide solution can be orchestrated in a very short time frame. Pertinent to this principle, TURFs on FADs are being considered because rights to FADs already exist and trades are occurring between the recreational sector and the commercial sector in this region. It is important to examine existing rights-based structures embodied in current use. For example, recreational anglers will pay cash and trade nonbillfish catch for the exclusive right to fish over FADs for an agreed-upon period of time. In other locations, recreational fishermen have built and installed FADs with the understanding from the local community that they have first rights to fish that FAD, and the small-scale fishers in the community can utilize the FAD at other times provided they release all billfish alive. Other payment mechanisms also have emerged from the many billfish tournaments in the region.

A number of details have to be worked out in the Caribbean pilot design, and enabling conditions need to be met before a full program of tradeable rights can be developed. In the near term, however, it has been proposed that the recreational sector contribute to a conservation fund that will advance those enabling conditions, register vessels and FADs, and begin the process towards a stronger, more tradeable rights system that compensates commercial fishermen for use of their FADs. While some trades are occurring, they are ad hoc and not transparent. It is also apparent that the payments for FAD use in certain ports have driven an increase in capacity to simply fish for payments. This described case is a good example of building on systems and incentives already in place and using them to move toward adaptive co-management that empowers both sectors to be surrogate regulators. 
Case Study 3: The Role of Key Actors in the Value Chain

A study by Bailey et al. (2016) investigates the influence of key actors in the value chain for tuna in South East Asia in order to identify engagement points for fishery interventions. Certification schemes are intended to contribute to sustainable development by establishing trading conditions that are transparent and equitable. This requires improved market access and strengthened producer organizations. In South East Asia, "middlemen" play a key role in fish trading and providing fishers with access to capital, infrastructure, and other services. This may result in market benefits not accruing to primary producers who engage in more sustainable practices, thereby not passing price incentives from the market down to the harvester. Research interviews and analysis were conducted in a Fair Trade USA fishery scheme operating for handline-caught yellowfin tuna from the Moluccas in Indonesia. The research shows that middlemen contribute but also control the full range of assets required to enable fishers to fulfil their value chain functions. It was observed that the introduction of a certification scheme has facilitated a reorganization of value chain structure in the fishery, and also has changed fishermen's perceptions of the resource and the market. The opportunities and challenges for such schemes to be a force for positive change still depend on fishermen/middlemen dynamics being considered.

This is an example of looking at multiple aspects of a project holistically to reduce cost, reduce conflict, and target interventions. If the middleman connection had been ignored, it is unlikely that the certification scheme would have been successful, as the benefits would not have been passed down to the fisher. 
Case Study 4: The Parties to the Nauru Agreement and the Development of the Vessel Day Scheme

The implementation or strengthening of rights-based management is often the result of a path or progression-from completely open access to regulated open access to limited entry (a weak right), and finally to stronger rights (Gentner 2018). The PNA and the vessel day scheme are a clear example of this. The process started with the adoption of the Nauru Agreement in 1982 to organize the management of fishery resources of contracting States' EEZs. This agreement established the PNA for the Cooperation in the Management of Fisheries of Common Interest. The main objective of this agreement was to give coastal State preference over access to resources, require/enhance development of domestic fisheries, develop ports and infrastructure, and provide for local employment. The Palau Arrangement (PA) came out of the PNA because of concerns that yellowfin tuna stocks were being overexploited and measures were needed to reduce harvests. The agreement capped vessel numbers initially at 164 and increased those numbers to 205 in 1993. It came into force in 1995. During this time period, there was a slight increase in fees, but the increase stalled at between 5 and 6 percent of landed value.

Before giving the PA much time to work, the Federated States of Micronesia Arrangement (FSMA) was established in 1985.The FSMA discounted access licenses and reciprocal access if the vessel would use local labor, buy local provisions, and offload locally (Havice 2010). However, the FSMA simply increased the license numbers without removing other licenses, so capacity increased. Unfortunately, the FSMA did not reach its goals of improving local economic conditions because there was a general lack of transparency and few development opportunities (Yeeting et al. 2016).

Additionally, neither agreement had any positive impact on stocks. While the PA limited the number of boats, it did not address capacity, and license holders began to increase their vessel size creating effort creep (Yeeting et al. 2016). Also, PNA countries were allowed to license new vessels within the cap on vessels, which further increased capacity. Technical capacity under the vessel cap also increased through the use of geo-referenced FADs. Catches continued to increase, albeit more slowly (Havice 2013, Yeeting et al. 2016). By 2000, the goal of increasing fishing fees for the members was still not being met (Yeeting et al. 2016).

The Vessel Day Scheme (VDS) grew out of the failure of these previous agreements to reduce pressure on the stock and improve local economic conditions through increased access fees and local infrastructure development. The PNA decided to cap total effort, eliminate limited entry, and create a transferable effort program (Squires et al. 2013). It was designed to generate a real limit on fishing days, thereby creating a demand for days and competition among users for those days (Yeeting et al. 2016). It was hoped the VDS would drive up access prices. The VDS eliminated limited entry and allows for new entrants as long as the new entrants can secure fishing days. The primary reason an effort limit was chosen over a catch limit was to ensure that monitoring of fishing activity was cost-effective. It is easier and usually less costly to monitor location and fishing time compared to monitoring harvests from DWFs that land their fish at ports outside of the region (Havice 2010, Yeeting et al. 2016). The PNA were not against 
tradable catch quotas, but knew the MCS infrastructure to monitor catches would be far more challenging (Havice 2013). Initially, the PNA had planned to ratchet down effort through time to reduce harvests to sustainable levels.

Another interesting motivating factor for developing the VDS was a desire to maintain control of fisheries management in the face of the newly created by the Western and Central Pacific Fisheries Commission (WCPFC) by (Havice 2013), which came into force in 2004 (Aranda et al. 2012). Yeeting et al. (2016) also point to a perceived erosion of State sovereignty as a motivating factor for creating the VDS. By developing and defining regional sovereignty over tuna in the EEZ of member countries, PNA prevented the WCPFC from usurping control (Dunn et al. 2006, Havice 2013). WCPFC recognized the VDS and made it binding at the RFMO level with a legislative instrument that was agreed to by consensus (Shanks 2010).

Implementation of the VDS generally followed four phases as identified by Yeeting et al. (2016). It was ratified in 2007, and the period from 2007 to 2010 was considered the first phase during which many design elements were still being worked out. It took three years to hammer out the allocation strategy (Shanks 2010). The second phase started in 2011 with full implementation of hard limits on Party Allowable Effort (PAE). The third phase began in 2012 and was characterized as full adoption by all parties. All members agreed to a benchmark price for vessel days, ensuring that access fees would increase. The fourth and final phase, which is still ongoing, began with a commitment to trade days across members, increase flexibility to more efficiently allocate effort, and stay within the Total Allowable Effort (TAE).

PNA/Pacifical Joint Venture. Recognizing the need to end recruitment overfishing of bigeye tuna and yellowfin tuna in the purse seine fishery over FADs, the PNA felt pressure could be placed on the industry by certifying "clean" skipjack tuna fisheries. Seeing weaknesses in the sustainability claims with pole and line fishing, the PNA moved to certify free school purse seine (PS) sets, which protect bigeye and yellowfin tuna juveniles (Yeeting et al. 2016). Approximately 60 percent of WCPO landings are from free school sets.

In order to pursue tuna conservation objectives and increase revenue to its member states, the PNA entered into a joint venture in 2010 with the Dutch-based Pacifical BV to promote and market MSC skipjack tuna (Yeeting et al. 2016). This was a 50/50 joint venture. If fishers were able to verifiably follow the MSC label rules, they would receive a 10 percent price premium at landing. Canneries that handled the MSC fish would receive a 3 percent premium for canning the product, and PNA/Pacifical BV would retain a 7 percent premium, for a total price premium of 14 percent over non-certified product (Yeeting et al. 2016).

MSC certification was granted in 2011, and the fishery received chain of custody certification in 2013 (Yeeting et al. 2016). It took two years from certification of the chain of custody to get the product in the marketplace. It is still too early to assess economic outcomes of this certification and joint venture. Annual net wholesale value is up to $\$ 4.5$ billion, and the PNA could generate up to five percent of net wholesale value with this label above the value of access fees (Yeeting et al. 2016). Control has been increased in two dimensions. First, the certification reinforces 
existing State-based MCS such as 100 percent observer coverage. The observer coverage allows the separation of FAD free catches from FAD catches, which the entire certification hinges upon. This additional coverage is expected to have spillover effects for the overall VDS MCS (Yeeting et al. 2016). Second, the certification program has increased transparency on where, when, and how a fish is caught and processed, which was one of the original goals of the Federated States of Micronesia Arrangement (Yeeting et al. 2016).

Assess and adapt: performance review of the VDS. Overall, the project has been quite successful and has demonstrated success for incentive-based management. Access fees have gone from less than 6 percent of landed value to 14 percent of landed value in a relatively short period of time, raising economic returns dramatically (Yeeting et al. 2016, Havice 2013). This has driven total access fees up by 280 percent (Havice 2013). Benchmark prices for access have increased to nearly $\$ 8,000 /$ day in 2015 (Yeeting et al. 2016). These increases meet one of the major goals of the VDS, and have strengthened the resolve of the parties (Yeeting et al. 2016). Additionally, the acceptance of the program by the WCPFC and the demonstrated success have increased the PNA's bargaining power with DWFNs (Yeeting et al. 2016).

While the VDS is largely viewed as a success, there have been several criticisms. These criticisms center around several design loopholes and a general inability of the program to improve stock conditions (Yeeting et al. 2016). There is still great concern about what is locally termed "effort creep," or increasing capacity within the definition of a fishing day (Yeeting et al. 2016, Havice 2013, PNA 2015). Another effort loophole arose when Tokelau became a party (Havice 2013). They entered and claimed 1,000 days, which was not accounted for in the allocation formula applied to other parties. This overallocation may be a trade-off to secure participation, but also represents further mortality on tuna stocks. Furthermore, the Tokelau experience may encourage other nations to join, and further increase effort.

In 2015, the PNA commissioned a full review of the VDS completed by Ragnar Arnason and Michael Harte (PNA 2015). Overall, they suggested separating the broader governance of the PA, NA, and FSMA from management of the VDS. Along these same lines, the management of the VDS should be organized much like a corporation with a strong VDS administrator governed by a board of directors (PNA 2015).

The primary goal of the VDS was to assert control over coastal State tuna resources and maximize the fee revenues for fisheries access. The reviewers concluded that maximizing fee revenue is a function of the stock size and the days available in the VDS (PNA 2015). While there was substantial uncertainty regarding the optimal number of days, they showed that there is room for significant growth in the value captured by fees.

To reach maximum fees, the PNA might need to increase fishing days (PNA 2015). If the TAE is raised, more bigeye tuna and yellowfin tuna will be caught unless there are effective measures to regulate FADs. The reviewers suggested using pricing schemes to address FAD effort, move to a harvest-based system with improved catch document schemes, or focus on technical solutions to FAD bycatch. 
To address these concerns and suggestions, the PNA has instituted both FAD charges and time/ area closures for FADs. Currently the FAD closure is four months long (Kumasi 2016). The FAD charge has two objectives: first, to reduce bigeye tuna overfishing by placing a disincentive on FAD use, which could eliminate the need for total FAD day limits or time/area closures; and second, to generate funds to pay for bigeye tuna conservation. The FAD charge is levied for each vessel using FADs and is set at $\$ 1,000$ per day on top of the VDS fee. The trial began in January of 2016; it is too early to assess its impact.

Instead of setting fees through a research committee, the reviewers also suggest encouraging a more robust market for days to develop (PNA 2015). To that end, they suggest that TAE shares be given for a longer duration. Also, transferability should be substantially increased and trades of PAE to other parties should not affect allocations of PAE in future years as it does now. Another potential solution to the bycatch problems is to include the longline fleet in the VDS system, and set fees-or allow the market to set fees-to minimize artificial distortions between fishing methods. Currently, the LL VDS is being implemented as a response to this advice (PNA 2016).

From an exclusivity standpoint, the reviewers and others have suggested improvements including permanent closures of high seas enclaves, or donut holes (Shanks 2010, PNA 2015). The reviewers also see the external competitive fringe as a threat to the value of the VDS, and the PNA should expand the coalition or seek their cooperation (PNA 2015).

The reviewers suggest that there are gains to be had with freer trades, and advocate making the VDS right more homogeneous so they can be used across EEZs. They also suggest free trading within the Palau Agreement parties, along with developing a framework that facilitates open trading. This would allow fishermen to switch their days across EEZs. The transfer of VDS between vessels should continue to be off-limits until a better way to account for individual vessel capacity differences can be developed. These trades must be transparent, and any changes or trades that impact others must be treated as public information. Trade prices should be reported, but treated as confidential information. The administrator should publish an annual report that summarizes trade information in a non-confidential way. This annual report should be reviewable and the administrator and the board should be required to clarify any questions (PNA 2015).

Finally, the reviewers discussed amending legal instruments to improve the VDS. They suggest amending the Palau Agreement or enter into a new integrated legal instrument allowing for a range of appropriate mechanisms to manage effort creep through remedying weaknesses in existing legal documents. Additionally, there may be a need for additional legal backing for the compliance enhancements suggested above. This may mean replacing the existing document or amending the existing legal arrangements (PNA 2015). 


\section{Case Study 5: Fishery Certification Schemes}

Certification schemes are defined as voluntary, non-discriminatory, independent auditing, and verification procedures incorporating reliable data. These often begin with FIPs in tuna fisheries, which are voluntary assessments of fishery performance and voluntary pledges to improve performance to reach certification. Often, a FIP alone is enough to grant access to better markets for product, and achieve a price premium. Certifiers act as a surrogate regulator in that they assess compliance with regulatory standards in a fishery. This may relieve burdens on fisheries administration by using market-based incentives to secure compliance with regulatory standards. A successful certification process results in an eco-label that communicates the quality of the product to the consumer. Certification may result in a premium to the product or allow access to a restricted market. Thus, market benefits are used to leverage improvements in sustainable fishing practices.

WWF (2012) reviews a number of private, independent certification schemes including Alaska Seafood Marketing Institute, Friends of the Sea, Iceland Responsible Fisheries, and the Marine Stewardship Council. There are other certifications schemes as well, including mandatory import/export schemes, supermarket/processing sector initiatives, and a whole host of other labeling schemes. Those are summarized in this FAO document: http://www.fao.org/ docrep/010/ai002e/AI002E14.htm

There is variability in the performance of certification (Gentner 2018). Some research shows positive impacts on the management and conduct of fishing. Also, certification can operate at the level of a fishery, not just a specific stock. This means it can encompass a wider assessment of fishing practices, and influence the governance of not just target species. Other research shows certification favors larger scale fishing operations in developed States over small-scale fisheries in developing States. High certification costs may deter small-scale fisheries. It is generally agreed that the benefits of certification are highly contextual.

Certification schemes are linked to other fisheries management tools. For example, fisheries using catch share schemes (a form of RBM) have been more likely to secure high certification scores (Parks et al. 2016). Generally, this is due to the fact that catch-based RBM programs need strong MCS and an enforceable TAC to be successful.

From a governance point of view, certification operates as a form of quasi-private regulation, and raises important concerns. These include the absence of any formal standards and control of certification schemes, the lack of liability of certifiers for their assessments, and scope for corruption or bias in the process. Tightening the control of certifiers and schemes could provide a strong stimulus to such schemes and increase confidence in the results. 


\section{Case Study 6: "ISDA Strategy"}

The "ISDA strategy" for Philippines tuna fisheries is another example of the potential for nonState regulators to design management regimes. This strategy advocates funding the provision of VMS for tuna vessels and a CDS, which can be used to help eliminate IUU fishing activities. The fund's investors would be repaid through the revitalization of a processing and distribution business producing premium seafood products (Barnes 2018). In the case of the Philippines, while tuna is a regionally managed fishery, the nearshore tuna fisheries are virtually unregulated due to budgetary constraints and limited regulatory capacity by local authorities. However, unilateral measures could have limited effect in multilateral fisheries subject to multiple jurisdictions.

Another example is the financing of a Nexus Blue scenario, which considers the provision of a "fisheries information management system" (FIMS) to the Philippines and WCPFC. This would enhance management capacity, but alone does not necessarily result in improved fish stocks. It is viewed as a lever or catalyst to regulatory change that would include fishery-wide vessel registration systems and the setting of maximum catch limits.

While such changes could be introduced without investment, the introduction of capital can overcome political or economic barriers to change. Other public-private partnership investments are usually targeted at the provision of improved supply chain infrastructure, such as less damaging gear, better catch storage, transport and processing facilities, and measures to cultivate brand and product value (marketing). 


\section{Case Study 7: Allocation Issues in International Fisheries}

The impact of institutional structures and regulatory logics can be illustrated by looking at how fishing opportunities are allocated.

International fisheries law has poorly defined approaches to allocation (Barnes 2018), and strongly favors historical fishing activities (Cox 2009, Serdy 2016). As such, it may be difficult to accommodate other socio-economic or conservation considerations, such as credit for conservation or sustainable fishing practices (Bailey et al. 2013). The introduction of RBM presents a challenge and opportunity to the allocation of fishing entitlements. RBM can use markets to distribute rights more efficiently. However, they can threaten existing distribution of fishing rights. The ISSF Cordoba Conference concluded that an effective allocation framework is fundamental to the implementation of rights-based management (ISSF 2011). There is a linkage between compliance and enforcement and allocation of fishing opportunities. If allocations are perceived as unfair, then there may be incentives to ignore restrictions or subvert the rules (Nielsen 2003). This means legitimacy (i.e., fair allocations) needs to be built into management regimes (ISSF 2011).

Initiatives are underway to develop allocation criteria in some RFMOs, and this may provide an opportunity for pressing for the inclusion of criteria to incentivize sustainable fishing. Participatory rights and allocations are a key lever to incentivize non-Members to adhere to RFMO measures. However, they remain contentious since new Members may require reductions in existing allocations and benefits. Also, more concrete allocation criteria would undermine the ability of individual States to negotiate more favorable allocation of fishing entitlements.

There are some general parameters that influence allocations under international law, but this is a negotiated process, heavily influenced by historic patterns of fishing. Legally, any State with a real interest in a fishery must be able to participate in an RFMO.

The UNFSA provides some parameters for participatory rights for States:

- Status of stocks and existing levels of fishing

- Respective interests and fishing patterns/practices of existing and new members

- Contributions to conservation and management

- Needs of dependent fishing communities; needs of dependent coastal States

- Interests of developing States in the region 
Case Study 8: Review of UNFSA—Reflective International Law-Making

Although international law can be difficult to formally amend, governance systems provide opportunities to reflect upon and recommend changes in international practices, either through RFMOs or State management regimes. The United Nations Review Conference for UNFSA found that improvements were still required in the management of marine capture fisheries (UNGA 2016). ${ }^{5}$ Its report called upon States to take measures, consistent with international law, to ensure that only fish caught in accordance with applicable conservation and management measures reach their markets, and to take steps consistent with international and domestic law to require those involved in fish trade to cooperate fully to this end. It presented a number of recommendations, including the adoption of market-related measures (Barnes 2018).

For management to be effective, there must be consistency between actions of States and those of RFMOs, with particular attention paid to landing of fish in ports other than the port of the flag State (Roheim 2008). This latter point indicates a potential weakness in securing strong chain of custody measures, which require greater use of catch documentations schemes (CDS) and other market-related measures. To this end, the FAO voluntary guidelines on CDS (FAO 20176) need implementation and support for initiatives such as the International Monitoring, Control and Surveillance Network for Fisheries-related Activities (IMCS Network). 
Case Study 9: Management Options and Investment Potential in IATTC

This case is a good example of a cost/benefit analysis of interventions in the Eastern Pacific Ocean to address recruitment overfishing of yellowfin tuna and bigeye tuna in purse seine fishery. The first question is whether there are short-term mechanisms to avoid longer time/ area closures and more precisely control mortality of these two species. The second question is whether the IATTC can establish a robust plan to address overcapacity of the purse seine sector, which is the underlying cause of excessive mortality of these two species.

There does seem to be enough dissipated rent to compensate the PS fleet as a side payment or under some sort of Coasian bargain. Currently, the purse seine fleet is losing $\$ 45$ million annually as a result of the closed season, and stakeholders are receptive to exploring alternatives to the current management regime (Maharaj 2019). Generally, the stakeholder meetings found that quota systems were preferred over day-based rights because of experience with Dolphin Mortality Limits (DML). Days at sea would not work for bigeye tuna because they are not uniformly distributed in PS sets over FADs. However, it might work for yellowfin tuna if they were coupled with FAD set limits or some other measure to control "effort creep." A sub-regional agreement might work, as only five countries catch 80 percent of tuna landings. The PS sector vehemently opposed a bigeye tuna tax, but fines or penalties for exceeding individual or country quotas were not opposed. Another option discussed was to form a bigeye tuna corporation that would own and manage PS bigeye tuna, and could trade quota with the longline (LL) fleet. It was very clear that all key actors want to avoid longer PS closures.

Using the outputs from the Fishery Performance Indicators, initial data collections, and the stakeholder input, the WWF commissioned a cost/benefit analysis of the use of country quotas for bigeye tuna and yellowfin tuna compared to longer purse seine closures. Bucaram (2017) conducted an ad hoc cost and earnings survey of the fleet and was able to estimate cash flow profiles for five vessel size classes. The study also estimated the costs of increased MCS, including electronic monitoring (EM), expanded annual observer coverage, and improved observer safety. The report estimates that compliance costs per vessel to be $\$ 13,467$ for boats that have observers already, and $\$ 24,054$ for vessels that do not currently carry observers. The net present value (NPV) of increasing observer coverage and security is $\$ 19,621 /$ vessel. That puts the total NPV of costs per vessel between $\$ 33,088$ and $\$ 43,675$ per boat depending on whether they currently carry observers.

While it is hoped that an IVQ would be tradable eventually, Bucaram (2017) modeled no trading and no rent gains due to trading and other features of tradable catch rights. Instead, the interventions were simply modeled as reductions in individual TACs. Any reduction in cost over a closure would be the flexibility to reduce bycatch of bigeye tuna and yellowfin tuna, and increase revenues by targeting skipjack tuna with less bycatch. From the analysis and with the costs of MCS included, all scenarios analyzed illustrated that, on average, vessels would be better off under the IVQ program compared to an expansion of the closure. Closures reduce flexibility, and reduced flexibility is costly. 
It is important to point out that adding a market for IVQ shares and allowing resource rents to return to the vessels would change that calculus dramatically, further favoring the IVQ.

WWF also commissioned another study to directly assess fleet capacity reduction measures that build off proposals submitted by IATTC members and interventions receiving favorable reception at stakeholder meetings in the region (Northern Economics 2018). Of the eight proposals analyzed, the study shows that transferable quota approaches result in a reduced fleet size that is close to the optimum. A similar alternative to ITQs is a uniform limit on small bigeye and yellowfin tunas for all vessels, in combination with improved monitoring on the vessels and at the processing plants. The uniform limit approach will constrain the least number of purse seine vessels. Industry-funded vessel buybacks under different scenarios were also analyzed, as such programs could be combined with other capacity-reduction initiatives and used to settle disputes. Addressing capacity reduction could be complicated in a multilateral context, and thus the study qualitatively analyzed "Small Steps" that, once implemented, will set the stage for additional actions to reduce capacity. Also, proposalssuch as the one submitted by Japan's (Prop-H-2-JPN) and modifications that will slowly decrease both the technological and actual vessel hold capacity—-were analyzed to provide different pathways to reform.

Recognizing that some adaptations will be required to change behavior, the study also analyzed pilot programs on individual vessel quotas (transferable) and voluntary capacity reduction. The latter includes incentives such as reduction in the length of the closed season for member countries taking steps to reduce fleet capacity, with compensation paid by vessel owners benefiting from the shorter closed season to those who choose not to fish. Pathways to reform could incorporate such pilot programs, which once implemented, would be modified and expanded using a stepwise approach to full adoption. Apart from incentives, improved accountability would be part of the pilot programs. For example, participants in a pilot IVQ program would have an exemption from the closed season and operate under increased monitoring. Similarly, vessels operating under a voluntary capacity reduction pilot program would receive the appropriate reduction in the closed season, and vessel owners not fishing would receive some compensation.

While the study examines proposals separately, it is clear there are different pathways to reform that can utilize a combination of these scenarios appropriately sequenced. Based on the outputs of these studies, WWF is developing two business cases to address excess capacity in this fishery and institute IVQs for bigeye and yellowfin tuna. Because the impacts are laid out clearly and were developed using extensive consultations with stakeholders, it is expected that one of the two cases will move forward (WWF 2018). Also, by engaging institutions that can take these transformations forward, study results can have additional impacts. For example, the IATTC is utilizing results of the capacity reduction analysis in its developing plan of action on fleet capacity management. Apart from use by the IATTC, these assessments can inform other tuna producing regions grappling with problems of overcapacity. 


\section{ENDNOTES}

1 The authors are listed in alphabetical order: James Anderson, Institute for Sustainable Food Systems, University of Florida; Frank Asche, Institute for Sustainable Food Systems and School of Forest Resources and Conservation, University of Florida; Richard Barnes, Faculty of Business, Law and Politics, University of Hull; Simon Bush, Environmental Policy Group, Wageningen University; Brad Gentner, Gentner Consulting Group; Charles Hufflett, Solander Pacific (Fiji) Ltd; Gary Libecap, Bren School of Environmental Science and Management and Department of Economics, University of California, Santa Barbara; Vishwanie Maharaj (technical editor and contributor), Oceans Team, World Wildlife Fund-Inc.; Lindie Nelson, International consultant, Economics and Fisheries Management; Wez Norris, Pacific Islands Forum Fisheries Agency; Giansandro Perotti, TRANSMARINA Manta, Ecuador; Uwe Tietze, International consultant, Micro-financing and fisheries management; Kelly Wachowicz, Catchinvest

2 See e.g., UNCLOS, Arts 56(2), 58(3), 60(3), and 80(2).

3 See Report of the resumed Review Conference on the Agreement for the Implementation of the Provisions of the United Nations Convention on the Law of the Sea of 10 December 1982 relating to the Conservation and Management of Straddling Fish Stocks and Highly Migratory Fish Stocks. UN Doc. A/CONF.210/2016/5, Annex Section C, paragraph 10

4 The documents for the OPP can be found at: http://www.fao.org/in-action/commonoceans/documents/en/?user_ extextender_option_list_1=60799.

5 See Report of the resumed Review Conference on the Agreement for the Implementation of the Provisions of the United Nations Convention on the Law of the Sea of 10 December 1982 relating to the Conservation and Management of Straddling Fish Stocks and Highly Migratory Fish Stocks. UN Doc. A/CONF.210/2016/5, Annex Section C, paragraph 10 


\section{PHOTO CREDITS}

Cover: Blue-fin tuna harvest in Eastern Mediterranean, Turkey. (C) zaferkizilkaya

Inside Front Cover: Yellowfin Tuna. La Paz, Mexico. (c) Brian」. Skerry / National Geographic Stock / WWF

Page ii: Deepsea fishing boat. (C) photomatz

Page viii: Fresh tuna ready to be sold. (c) imv

Page 4: A fishport worker crosses a plank to unload the day's catch of Yellow Fin Tuna. General Santos, Philippines. (c) h3ct02

Page 10: Tuna fishing "Almadraba" style off shore Tarifa, Spain. (C) Jorge Bartolome / WWF

Page 12: Northern bluefin tuna off the coast of Spain. (c) Brian J. Skerry / National Geographic Stock / WWF

Page 16: Tuna boats. Port Lincoln wharf, Australia. (c) John White Photos / Alamy Stock Photo

Page 20: Yellowfin tuna fishing catch. Indian Ocean, South of Java and Bali. (c) Simon Buxton / WWF

Page 22: Prospective buyers inspect tuna. Tokyo, Japan. (C) SeanPavonePhoto

Page 26: Broadbill swordfish dead in fishing net. San Pietro, Italy. (C) Brian J. Skerry / National Geographic Stock / WWF

Page 28: Emptying a mesh full of Orange roughy into a trawler. (c) AFMA

Page 32: Tunas in seine net. Atlantic ocean. (c) Hélène Petit / WWF

Page 36: Stevedores unload tuna from a fishing vessel. General Santos, Southern Mindanao, Philippines. (c) Jürgen Freund / WWF

Page 42: Benoa tuna fish landing from longliner boats, Benoa, Bali, Indonesia. (c) Jürgen Freund / WWF

Inside Back Cover: School of Tuna. (c) GuidoMontaldo 

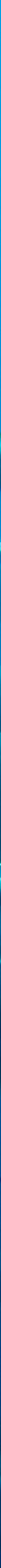
Fisheries that intersect with the high seas, or areas beyond national jurisdictions (ABNJ), are ecologically, institutionally, and politically complex. These fisheries also generate enormous economic and social benefits and have the potential to generate even greater benefits and wealth under improved management regimes that incorporate incentives. While the need for incentives is critical to make up for the gaps in high seas governance regimes and multilateral processes, the gaps themselves make it impossible to achieve first best solutions. Thus, a new theory of change for ABNJ fisheries is needed in a way that achieves sustainable and equitable management. Drawing on the multidisciplinary literature and insights from the Common Oceans Global Think Tank (GloTT) on ABNJ fisheries, this publication presents nine principles for utilizing "smart mixes" of regulatory and incentive-based tools (instruments). GloTT deliberations on the lessons learned from developing instruments under the World Bank's Ocean Partnerships Project, insights from existing innovative incentive programs applied to ABNJ fisheries, and the broader experience of the GloTT members were essential in creating this vison for future reform.
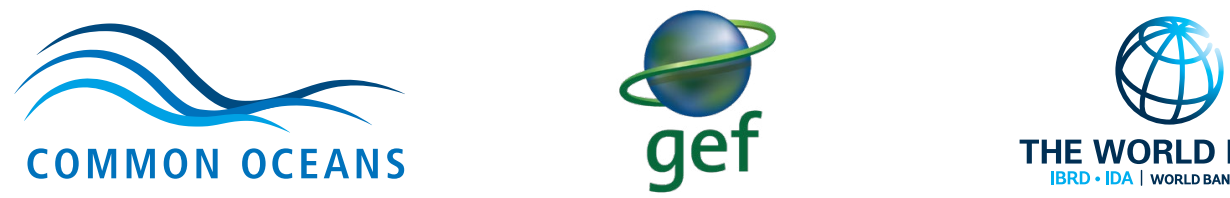